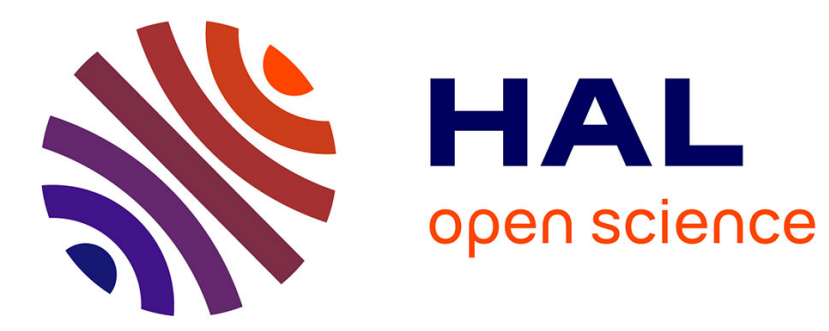

\title{
Glass-windowed ultrasound transducers
}

Torstein Yddal, Odd Helge Gilja, Sandy Cochran, Michiel Postema, Spiros Kotopoulis

\section{To cite this version:}

Torstein Yddal, Odd Helge Gilja, Sandy Cochran, Michiel Postema, Spiros Kotopoulis. Glasswindowed ultrasound transducers. Ultrasonics, 2016, 68, pp.108-119. 10.1016/j.ultras.2016.02.005 . hal-03192839

\section{HAL Id: hal-03192839 \\ https://hal.science/hal-03192839}

Submitted on 12 Apr 2021

HAL is a multi-disciplinary open access archive for the deposit and dissemination of scientific research documents, whether they are published or not. The documents may come from teaching and research institutions in France or abroad, or from public or private research centers.
L'archive ouverte pluridisciplinaire HAL, est destinée au dépôt et à la diffusion de documents scientifiques de niveau recherche, publiés ou non, émanant des établissements d'enseignement et de recherche français ou étrangers, des laboratoires publics ou privés.

\section{(이) $\$$}

Distributed under a Creative Commons Attribution - NonCommercial - NoDerivatives| 4.0 


\section{Glass-windowed ultrasound transducers}

2 Tostein Yddal ${ }^{\mathrm{a}, \mathrm{b}}$, Odd Helge Gilja ${ }^{\mathrm{b}, \mathrm{c}}$, Sandy Cochran $^{\mathrm{d}}$, Michiel Postema ${ }^{\mathrm{a}, \mathrm{e}}$, and Spiros

tment of Physics and Technology, University of Bergen, Allégaten 55, 5007 Bergen, Norway

b National Centre for Ultrasound in Gastroenterology, Haukeland University Hospital, Jonas Lies vei 65, 5021 Bergen, Norway

${ }^{c}$ Department of Clinical Medicine, University of Bergen, Jonas Lies vei 65, 5021 Bergen, Norway

${ }^{\mathrm{d}}$ School of Engineering, University of Glasgow, 6.03 James Watt South Building, Glasgow, G12 8QQ, United Kingdom

${ }^{\mathrm{e}}$ School of Electrical and Information Engineering, Chamber of Mines Building, University of the Witwatersrand, 1 Jan Smuts Avenue, Braamfontein, Johannesburg 2050, South Africa

* Corresponding Author

\section{Abstract}

In research and industrial processes, it is increasingly common practice to combine multiple measurement modalities. Nevertheless, experimental tools that allow the colinear combination of optical and ultrasonic transmission have rarely been reported. The aim of this study was to develop and characterise a water-matched ultrasound transducer architecture using standard components, with a central optical window larger than $10 \mathrm{~mm}$ in diameter allowing for optical transmission. The window can be used to place illumination or imaging apparatus such as light guides, miniature cameras, or microscope objectives, simplifying experimental setups.

Four design variations of a basic architecture were fabricated and characterised with the objective to assess whether the variations influence the acoustic output. The basic architecture consisted of a piezoelectric ring and a glass disc, with an aluminium casing. The designs differed in piezoelectric element dimensions: inner diameter, $\mathrm{ID}=10 \mathrm{~mm}$, outer diameter, $\mathrm{OD}=25 \mathrm{~mm}$, thickness, $\mathrm{TH}=4 \mathrm{~mm}$ or $\mathrm{ID}=20 \mathrm{~mm}$, $\mathrm{OD}=40 \mathrm{~mm}, \mathrm{TH}=5 \mathrm{~mm}$; glass disc dimensions $\mathrm{OD}=20-50 \mathrm{~mm}, \mathrm{TH}=2-4 \mathrm{~mm}$; and details of assembly.

The transducers' frequency responses were characterised using electrical impedance spectroscopy and pulse-echo measurements, the acoustic propagation pattern using acoustic pressure field scans, the acoustic power output using radiation force balance measurements, and the acoustic pressure using a needle hydrophone. Depending on the design and piezoelectric element dimensions, the resonance frequency was in the range $350-630 \mathrm{kHz}$, the $-6 \mathrm{~dB}$ bandwidth was in the range $87-97 \%$, acoustic output power exceeded $1 \mathrm{~W}$, and acoustic pressure exceeded $1 \mathrm{MPa}$ peak-to-peak.

$3 \mathrm{D}$ stress simulations were performed to predict the isostatic pressure required to induce material failure and 4D acoustic simulations. The pressure simulations indicated that specific design variations could sustain isostatic pressures up to 4.8 MPa.The acoustic simulations were able to predict the behaviour of the fabricated devices. A total of 480 simulations, varying material dimensions (piezoelectric ring ID, glass disc diameter, glass thickness) and drive frequency indicated that the emitted acoustic profile varies nonlinearly with these parameters. 
Keywords: ultrasound transducer, de-fouling, optical window, acoustic field simulation

\section{Introduction}

In research and industrial processes, it is increasingly common to combine multiple measurement modalities. Nevertheless, experimental tools that allow the co-linear combination of optical and ultrasonic transmission are rare [1]. Hence, the aim of this study was to develop and characterise a water-matched ultrasound transducer architecture, with a central optical window larger than $10 \mathrm{~mm}$ in diameter, which allows optical transmission.

Such a device could be used in research applications such as chemical dissolution, where the window would allow collinear optical spectroscopy [2], and flow metering [3], [4], where the optical window would allow illumination or imaging of flow and contamination using digital cameras. Adding ultrasound transmission elements to the optical examination port in a pipeline could prevent fouling by inducing inertial or stable cavitation [5], and allow Doppler based velocity measurements [6]. Adding an optical window in a single element ultrasound transducer creates a means to simplify experimental configurations by illuminating, imaging, or measuring through the ultrasound transducer.

To achieve simultaneous optical imaging and ultrasonic sonication or detection, several experimental configurations have previously been designed, such as applying ultrasound at obtuse angles and adding wave-guides to align optical and acoustic fields when visualising ultrasonic effects using microscopes [7]-[11]. However, these configurations require time-consuming alignment techniques and changes in drive frequency or number of pulses requires re-alignment with the optical field. A transducer design allowing trans- and co-linear optical visualisation in the acoustic propagation direction would reduce complexity and provide possibilities for new experimental configuration for research and industrial applications.

Previously, only one type of optically transparent ultrasound transducer has been reported, to our knowledge. This design is based on lithium niobate (LNO) crystals coated with transparent indium tin oxide (ITO) electrodes with resonance frequencies of 6.3 and 7.1 MHz [1]. The device has no case or backing and is intended for use in particle manipulation in microfluidic devices, producing output pressures of up to $0.5 \mathrm{MPa}$. The $\sim 600 \mathrm{~nm}$ thick ITO electrodes affected the optical transmittance resulting in non-linear wavelength-dependent transmission. The electrodes are also susceptible to chemical and contact damage, and do not work under isostatic pressures surpassing $110 \mathrm{MPa}$ [12]. Furthermore, ITO deposition is more complicated and costly than more common electrode coatings such as conductive silver paint or vacuum-deposited gold.

Here, an ultrasound transducer architecture is presented, and four design variations based on it, with a circular optical window with diameter 10 or $20 \mathrm{~mm}$, where the piezoelectric element is encased within the device. The fabrication procedure is described for all the designs. Their frequency responses were characterised using electrical impedance spectroscopy and pulse-echo measurements, the acoustic propagation pattern using acoustic pressure field scans, the acoustic power output using radiation force balance measurements, and the acoustic pressure output using a needle hydrophone. 3D stress simulations were also performed to predict the isostatic 
pressure required to induce material failure and 4D acoustic simulations to assess the possibility to simulate and hence optimise the transducer response.

\subsection{Materials and Methods}

The design criterion of the device was to allow the insertion of optical devices such as microscope objectives with long working distances (> $10 \mathrm{~mm}$ ), small-aperture cameras such as endoscopic cameras, and fibre or liquid light guides into the transducer to image or illuminate the test medium through the optical window. Based on in-house hardware and experimental configurations, the minimum required window size was determined to be more than $10 \mathrm{~mm}$ in diameter and the maximum device diameter to be approximately $70 \mathrm{~mm}$. The acoustic requirements were for the point of highest acoustic pressure to be located collinearly with the centre of the optical window between $0-40 \mathrm{~mm}$ from the surface of the device; for a bandwidth of $>60 \%$ to allow a single device to operate at multiple frequencies; and for acoustic pressure output to exceed $1 \mathrm{MPa}$. The device was also required to sustain as high an isostatic pressure as possible for operation in oil and gas pipes. Furthermore, it should consist of commercially available "off-the-shelf" components that would not require specialised modification, allowing any research or industry laboratory to manufacture such a device.

\subsection{Design}

An architecture consisting of as few components as possible, with adhesive joining, was chosen to reduce complexity and manufacturing costs. It was based on conventional single-element ultrasound transducer architecture [13], [14]. The changes made were to use a piezoelectric ring to replace the piezoelectric disc and to add a glass disc. This architecture was chosen as it involves only geometric shapes i.e., discs, rings, and cylinders, that can be purchased commercially and aligned easily during assembly without specialised hardware.

Four designs were evaluated to determine the effect of geometry differences on the acoustic output and mechanical strength. Graphical renderings and cross-sections of the designs can be seen in Figure 1A. Figure 1B shows the parameters that can be varied using this construction whilst Table 1 provides the dimensions used in the prototype transducers. The outer diameters (ODs) and inner diameters (IDs) of the piezoelectric discs were, respectively, $40 \mathrm{~mm}$ and $20 \mathrm{~mm}$ for two of the designs, and $25 \mathrm{~mm}$ and $10 \mathrm{~mm}$ for the other two designs. Including the adhesive and case, this resulted in assembled device outer diameters of, respectively, $50 \mathrm{~mm}$ and $38 \mathrm{~mm}$. For this architecture the chosen piezoelectric material was PZ54 (Meggit Sensing Systems: Ferroperm Piezoceramics, Kvistgaard, Denmark) due to its low cost, $€ 11-14$ per ring and commercial availability; high mechanical quality factor, $\mathrm{Q}_{\mathrm{m}}>1500$; relatively high piezoelectric charge coefficient, $\mathrm{d}_{33}=500 \times 10^{-12} \mathrm{C} / \mathrm{N}$; and acceptable maximum operating temperature, $\mathrm{T}=130^{\circ} \mathrm{C}$. Theoretically, the acoustic impedance of the piezoelectric material would allow the glass disc to act as an acoustic impedance matching layer for acoustic propagation into water.

Based on the theoretical acoustic impedances of the materials, $\mathrm{Z}_{\mathrm{PZT}} \approx 33 \mathrm{MRayl}$ and $\mathrm{Z}_{\text {water }} \approx 1.5 \mathrm{MRayl}$, the optimum acoustic impedance of the matching layer is 7.0 MRayl. The acoustic impedance of quartz glass is in the range 10 - 15 MRayl, higher than the required value, but still of benefit in increasing the acoustic transmission into water from $17 \%$ to $30 \%$. $\mathrm{Q}_{\mathrm{m}}>1500$ indicates low internal damping in the piezoceramic, reducing internal heating and allowing long pulse durations. The 
piezoelectric charge coefficient was one of the highest in comparison to other available materials with the required value of $\mathrm{Q}_{\mathrm{m}}$. Optical grade synthetic fused quartz discs $\left(\mathrm{SiCl}_{4}\right)$ (H. Baumbach \& Co. Ltd, Ipswich, United Kingdom) were used as the glass discs for all transducers.

Based on the thickness of the piezoelectric rings, their theoretical centre frequencies were $\mathrm{f}_{\mathrm{c}}=400 \mathrm{kHz}$ for $5 \mathrm{~mm}$ thick elements and $\mathrm{f}_{\mathrm{c}}=500 \mathrm{kHz}$ for $4 \mathrm{~mm}$ thick elements. Using these parameters the ideal glass thickness, based on $1 / 4 \lambda$ estimation [13], is $3.4 \mathrm{~mm}$ at $400 \mathrm{kHz}$, and $2.75 \mathrm{~mm}$ at $500 \mathrm{kHz}$. In the prototypes, the closest thicknesses available practically were used.

Design 1 consisted of the 40-mm OD PZ54 ring and the thinnest (TH=2 mm) and largest diameter $(50 \mathrm{~mm})$ glass disc, which was bonded directly to the top of the aluminium transducer casing. The glass was $1.4 \mathrm{~mm}$ thinner (41\% lower) than the theoretical optimum thickness. Design 2 had the thickest glass plate $(\mathrm{TH}=4 \mathrm{~mm})$ with a diameter equal to the PZ54 ring $(\mathrm{OD}=40 \mathrm{~mm})$. In this design the glass was bonded to the PZT ring within the casing. The glass was $0.6 \mathrm{~mm}$ thicker ( $18 \%$ higher) than the ideal thickness. Designs 3 and 4 consisted of 25-mm OD PZT elements and both used $3 \mathrm{~mm}$ thick glass discs. The glass thickness was $0.25 \mathrm{~mm}$ thicker $(9 \%$ higher) than the theoretical optimum. The diameter of the glass disc in Design 3 was the same as the PZ54 ring $(\mathrm{OD}=25 \mathrm{~mm})$. Design 4 used a $30 \mathrm{~mm}$ diameter glass disc, 5mm larger than the OD of the PZ54.

These variables were chosen to evaluate the effect of design variations on the acoustic output and mechanical strength.

\subsection{Construction}

Designs 2-4 used identical construction processes, whereas Design 1 required a revised order of construction to allow glass bonding to the outer edge of the aluminium case.

Figure 2 shows the steps used to construct the devices. Designs 2-4 were constructed as follows. The central hole of a PZ54 ring was filled by hand with modelling clay (Dream Dough ${ }^{\mathrm{TM}}$, Sense Försäljning AB, Jordbro, Sweden) (Fig. 2A) to prevent epoxy seepage onto the corresponding glass area during the later stages of assembly. The hole was filled with clay by initially placing the PZ54 ring on a flat surface, then pushing and compressing the clay into the hole with the thumb until no volume change was observed and the entire volume of the PZ54 ring hole was full. The ring was then removed from the flat surface and held by the outer circumference and excess clay was added to the upper side of the hole and gently forced downwards allowing a small dimple ( $\sim 3 \mathrm{~mm}$ dome) to protrude from the bottom of the ring. The upper surface was left unmodified. This ensured complete hole coverage when the PZ54 ring was bonded to the glass disc.

EpoFix epoxy (Struers A/S, Ballerup, Denmark) was prepared according to the manufacturer's instructions and was degassed in a disposable plastic beaker by cycling between $500 \mathrm{~Pa}$ and $0.1 \mathrm{MPa}$ with 30 second waits at each pressure. Degassing was complete when no more air bubbles were observed at $500 \mathrm{~Pa}$, requiring $10-15$ cycles. The degassed epoxy was poured into the central body of a 5 mL Omnifix Solo ${ }^{\circledR}$ syringe (B.Braun Melsungen AG, Melsungen, Germany) by removing the injection piston and placing a finger on the exit port to prevent seepage. The epoxy was poured ensuring continuous surface contact from the degassing beaker to the syringe body. A total of $\sim 5 \mathrm{~mL}$ was poured into the syringe to avoid a large headspace. The injection piston was then placed back into the main body and a 21 
gauge, $2.54 \mathrm{~cm}$ long Sterican ${ }^{\circledR}$ needle (B.Braun Melsungen AG, op. cit.) was placed over the injection nozzle.

The epoxy was injected onto the glass disc, placed on a glass working-surface, whilst avoiding contact between the needle and glass disc. The epoxy was injected as a continuous single ring approximately $2 \mathrm{~mm}$ wide concentrically aligned with the middle of the corresponding PZ54 ring location, i.e., with a diameter of $30 \mathrm{~mm}$ for Design 2, and $15 \mathrm{~mm}$ for Designs 3 and 4 (Fig. 2B). The PZ54 ring was placed on the glass disc ensuring the lower dome of the modelling clay contacted the centre of the disc first. Once in contact, the PZ54 ring and clay were uniformly pressed onto the glass. Proper contact was continuously observed through the glass working surface. Air pockets between the PZ54 ring and glass surface were removed by applying pressure on the PZ54 ring above them and observing the distribution of epoxy through the glass working-surface. Once homogenous epoxy spread and contact was achieved a $2 \mathrm{~kg}$ weight was placed on the PZ54 ring and the assembly was left for the epoxy to cure at room temperature for $24 \mathrm{~h}$.

Once curing was complete, the modelling clay was removed by hand. Because of the oil content of the modelling clay, the epoxy did not bond fully to it. Residual modelling clay that had partially bonded to the epoxy was removed using a scalpel whilst avoiding damage to the glass disc. Excess epoxy between the PZ54 ring OD and the glass disc was removed in a region of width $2 \mathrm{~mm}$ using a scalpel and scraping action to expose the edge of the electrode. Conductive access to this electrode between the glass and the PZ54 ring was checked using a multimeter. A resistance of $0 \Omega$ was targeted. The entire stack was then cleaned using isopropyl alcohol (IPA, $\mathrm{C}_{3} \mathrm{H}_{8} \mathrm{O}$ ) to remove residual oil left behind on the glass from the modelling clay.

A 3-cm long, micro-coaxial cable (CXA3607-50, Piezo-Metrics, Inc., St. George, Utah, USA) was glued to the edge of the surface electrodes using silver-loaded epoxy (Elektron Technology, Cambridge, United Kingdom) and the PZ54 - glass stack was placed in an oven at $100^{\circ} \mathrm{C}$ for $15 \mathrm{~min}$ to cure the silver-loaded epoxy and attain maximum conductivity (Fig. 2C). The stack was left for $2 \mathrm{hr}$ to cool to room temperature before proceeding. The exposed end of the micro-coaxial was spliced and soldered to a 30-cm long coaxial cable of larger diameter (RG178PE, RS Components, Corby, Northants, United Kingdom).

Next, the PZ54 - glass stack was placed on adhesive UV-release tape (Adwill D-202, Lintec Corporation, Tokyo, Japan), glass-side down, ensuring no gaps or air pockets were visible between the tape and glass surface. An aluminium cylinder was concentrically aligned around the stack ensuring no contact between the stack and cylinder. A $2 \mathrm{~mm}$ diameter hole was drilled into the cylinder wall for cable routing (Fig. 2D). The UV tape ensured that the front face of the aluminium case and the piezoelectric-glass disc remained aligned and that the Epofix epoxy that was added (Fig. 2E) did not seep out or on to the glass surface. The PZ54 - glass stack was bonded to the case using Epofix epoxy (prepared as previously described) by filling the gap between the case and PZ54 - glass stack up to the upper surface of the stack and left to cure for $24 \mathrm{hr}$. The tape was removed by exposing it to UV light at $365 \mathrm{~nm}$ wavelength (UPV PL Handheld, Company Seven, Montpelier, MD, USA) for $10 \mathrm{~min}$. In the last step, the RG178PE cable was threaded through the $2 \mathrm{~mm}$ hole and a BNC connector was attached to the end of the cable. The gap between the case and RG178PE cable was sealed with 5-minute epoxy (Unibond Super Epoxy, Henkel AG \& Co. KGaA, Düsseldorf, Germany) and the back of the case was closed off using a poly(methyl methacrylate) disc (PMMA) bonded in place with 5-minute epoxy 

device.

Design 1 was built using the same steps but with small changes to ensure better alignment and adhesion due to the larger diameter of the glass disc. First, the microcoaxial / RG178PE cable combination was bonded onto the edges of the upper and lower electrodes. The PZ54 ring, without the glass disc, was placed on UV-release tape (Adwill D-202, op. cit.), bonded to the case, and left to cure for $24 \mathrm{hr}$ at room temperature (Fig. 2C - E). The UV tape was removed and the hole in the middle of the ring was sealed with modelling clay. The glass was bonded in place (Fig. 2A - B) using the techniques previously described.

\subsection{Characterisation}

\subsubsection{Frequency Characterisation}

Frequency characterisation was performed to determine the electrical efficiency of the transducers and their operating frequencies. The frequency response of the transducers was characterised using electrical impedance spectroscopy and pulse-echo measurements. Electrical impedance spectroscopy was performed using an impedance analyser (4294A, Agilent Technologies/Keysight, Santa Clara, CA, USA) with a 50- $\Omega$ source impedance. During measurement, the transducers were immersed in a 500-ml beaker filled with de-gassed water. The acoustic propagation direction was towards the bottom of the beaker. The transducer was clamped in place using an electrically insulated clamp contacting the aluminium case. The transducer was placed approximately $8 \mathrm{~cm}$ from the bottom of the beaker. A $10 \mathrm{~mm}$ thick ultrasoundabsorbing disc (Aptflex F48, Precision Acoustics Ltd, Dorchester, Dorset, United Kingdom) was placed at the bottom of the beaker to prevent acoustic reflections interfering with the electrical impedance measurements. The echo reduction was $\sim 40 \mathrm{~dB}$.

The electrical reflection coefficient magnitude $(\delta)$ was calculated using:

$$
=\sqrt{\left(\frac{R^{2} Z_{0}^{2}+X^{2}}{\left(R+Z_{0}\right)^{2}+X^{2}}\right)^{2}+\left(\frac{2 Z_{0} X}{\left(R+Z_{0}\right)^{2}+X^{2}}\right)^{2}},
$$

where $\mathrm{Z}_{0}$ is the source impedance, and $R$ and $X$ are the measured electrical resistance and reactance, respectively. $\delta=1$ is equivalent to $100 \%$ electrical reflection and $\delta=0$ is equivalent to $0 \%$ electrical reflection, hence perfect electrical impedance matching to the $50 \Omega$ resistance of the driving source. The reflection coefficient magnitude spectrum has been shown to be a good indicator of transducer peak frequency, $f_{\mathrm{p}}$, bandwidth, $\mathrm{BW}_{\mathrm{f}}$, and acoustic efficiency with frequency [15].

Based on the ASTM guidelines [16], the pulse-echo method was used to determine the working frequency and bandwidth of the ultrasound transducer in situ. This data was compared to the electrical impedance measurements. The transducer was placed in a 2201 water bath facing a stainless steel plate of thickness $20 \mathrm{~mm}$, equivalent to $1.4 \lambda$ at $400 \mathrm{kHz}$, positioned $20 \mathrm{~cm}$ away from the surface of the ultrasound transducer. The stainless steel plate acted as an acoustic reflector, reflecting $\sim 88 \%$ of the transmitted energy, based on the acoustic impedance between it and water [17]. The device was driven by a $10 \mathrm{~V}_{\mathrm{pp}}$, 5-cycle burst sine wave with a $5 \mathrm{~ms}$ pulse repetition period generated by a waveform generator (33500B, Agilent Technologies/Keysight), and connected in parallel to an oscilloscope (WaveJet 354a, Teledyne LeCroy SA, Geneva, Switzerland) which was used to monitor the amplitude of the drive signal and which did not provide any additional loading. A total of five 
cycles was chosen as this was the minimum number required to reach the maximum peak-to-peak pressure in the transient wave for a given drive voltage.

The peak-to-peak amplitude of the echo was measured at drive frequencies in the range $0.1-1.0 \mathrm{MHz}$ with 1000 samples, yielding a step size of $1 \mathrm{kHz}$. Based on these results the following equations were used to determine the bandwidth $(B W)$, centre frequency $\left(f_{c}\right)$, and the mechanical quality factor $\left(Q_{\mathrm{m}}\right)$ :

$$
\begin{aligned}
& \mathrm{BW}_{\mathrm{f}}[\mathrm{kHz}]=f_{u} \quad f_{l} \\
& \mathrm{BW}_{\%}=\frac{\mathrm{BW}_{\mathrm{f}}}{f_{c}} \times 100
\end{aligned}
$$

$$
\begin{aligned}
& f_{c}=\frac{f_{u}+f_{l}}{2} \\
& \mathrm{Q}_{\mathrm{m}}=\frac{\mathrm{BW}}{f_{p}}
\end{aligned}
$$

where $f_{\mathrm{u}}$ and $f_{1}$ are the $-6 \mathrm{~dB}$ upper and lower frequency cut-offs. $f_{\mathrm{p}}$ was determined as the frequency of highest acoustic echo amplitude.

\subsubsection{Acoustic pressure field characterisation}

Acoustic pressure field characterisation was performed to determine the location and dimensions of the acoustic maxima. The acoustic pressure field was characterised using a custom made 2201 ultrasound characterisation tank with dimensions $500 \mathrm{~mm}$ $\times 980 \mathrm{~mm} \times 450 \mathrm{~mm}$ based on three orthogonally mounted linear stages. A PVDF needle hydrophone (Precision Acoustics Ltd, op. cit.) with an effective diameter of $200-\mu \mathrm{m}$ connected to a submersible pre-amplifier (HP series, Precision Acoustics Ltd. op. cit.) was used to sample the acoustic pressure in 4D ( $x-, y-, z_{-}$axis, and time) with a spatial sampling step of $500 \mu \mathrm{m}$. This resulted in a sampling step size between $1.19-2.14 \times$ the operating wavelength. The transducers were driven at their resonance frequencies $\left(f_{\mathrm{p}}\right)$ using a $1 \mathrm{~V}_{\mathrm{pp}}$, 5-cycle burst sine wave with a $1 \mathrm{~ms}$ pulse repetition duration via the $33500 \mathrm{~B}$ waveform generator connected to a $200 \mathrm{~W}$ linear class-A power amplifier with $53 \mathrm{~dB}$ gain (PA200-12, Precision Acoustics Ltd., op. cit.) through a $-20 \mathrm{~dB}$ attenuator. The peak-to-peak voltage, $\mathrm{V}_{\mathrm{pp}}$, was then mapped in $2 \mathrm{D}$ to determine the acoustic pressure field. For each transducer, three 2D scans were performed, one across the centre of the transducer in the propagation plane axis, one cross section performed $<1 \mathrm{~mm}$ from the face of the transducer, and one normal cross section at the distance of highest peak-to-peak pressure.

\subsubsection{Acoustic power and pressure measurements}

Acoustic power measurements were performed to compare the power output of the design variations. The power output was measured with a bespoke radiation force balance, based on the IEC 61161 standard [18]. The radiation force balance configuration is valid for frequencies in the range $0.5-25 \mathrm{MHz}$ and acoustic power up to $1 \mathrm{~W}$. The transducers were driven using a continuous wave at their peak frequencies, $f_{p}$, via the combination of the $33500 \mathrm{~B}$ waveform generator and PA200-12 power amplifier. The transducer was positioned radiating downwards in degassed water towards a 10mm thick acoustic absorber (Aptflex F28, Precision Acoustics 
Ltd., op. cit.), attached to a high-precision balance (SE300D, VWR International, Radnor, PA, USA). Acoustic power was calculated using:

$P=c \times m \times g$,

where $c$ is the speed of sound in the propagating media, $m$ is the measured mass, and $g$ is the gravitational constant. To compensate for thermal and other drifts, extrapolated on and off balance readings were performed [19]. The transducer was turned on and off sequentially for 20 seconds, five times. Specifically, the measurement was started at time $T=0 \mathrm{~s}$ with $20 \mathrm{~s}$ off time. The transducer was then powered on from $T=20 \mathrm{~s}$ to $T=40 \mathrm{~s}$. A complete, single measurement took $200 \mathrm{~s}$. Linear extrapolation was performed following UK National Physics Laboratory guidelines [20]. Using the first $40 \mathrm{~s}$ as an example, the extrapolated acoustic power, $P_{e x}$, was calculated by:

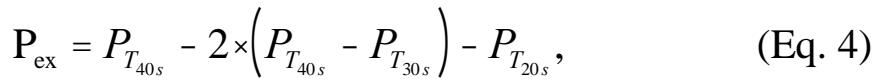

353 where $P_{T_{X X S}}$ is the power at a given time $(X X s)$ from the start of the measurement. Each measurement was repeated 5 times.

Acoustic pressures were calculated using the mean value of $P_{e x}$ and the full width at half maximum (FWHM) area, $A_{\mathrm{FWHM}}$, from the field scan performed in the focus of the transducers using the equation:

$$
p=\sqrt{\frac{P_{0} c_{d w}}{A_{\mathrm{FWHM}}}},
$$

where ${ }_{0}$ and $c_{d w}$ are the density and speed of sound of distilled water, respectively.

To validate the results, each transducer was placed in the calibration tank and driven using a 5-cycle burst sine wave with a $1 \mathrm{~ms}$ pulse repetition duration at the transducer's frequency of peak output via the 33500B and PA200-12 combination. A calibrated PVDF needle hydrophone (Precision Acoustics, Ltd., op. cit.) was positioned at the acoustic focus, its 1-mm diameter being $38.0 \%$ of the wavelength of $2.63 \mathrm{~mm}$ at the maximum frequency under investigation. Then the waveform generator voltage output was increased incrementally from $0.1 \mathrm{~V}_{\mathrm{pp}}$ to $5.0 \mathrm{~V}_{\mathrm{pp}}$ in $0.2 \mathrm{~V}_{\mathrm{pp}}$ steps and the peak-to-peak acoustic pressure was recorded.

\subsubsection{Thermal measurements}

Thermal measurements were performed to determine if the acoustic output of the architecture and the specific designs based on it was limited by heating of the PZ54 element. Heating was evaluated by placing the devices in the 2201 water-tank and driving them at $1 \mathrm{~W}$ acoustic output power for $60 \mathrm{~s}$ using a continuous wave at their respective values of $f_{p}$ using the $33500 \mathrm{~B}$ and PA200-12 combination. Afterwards, the transducers were immediately removed from the water-tank, dried using a paper towel in a process taking no more than $2 \mathrm{~s}$, and the entire surface of each transducer case and glass disks was scanned using an infrared temperature gauge (Art. No.: 36-5737, 
Clas Ohlson, Oslo, Norway). The maximum temperature of the case and glass disc was recorded. The process was repeated 5 times following a wait period of $\sim 30 \mathrm{~min}$ between each measurement allowing the transducer maximum surface temperature to

\section{Simulations}

\subsection{Acoustic pressure field simulations}

The acoustic fields were simulated using the PZFlex 2014 finite element analysis (FEA) software package (Thornton Tomasetti, New York, NY, USA) on a multicore Windows Xeon-based workstation. This package was selected because the authors have previous experience with it. An axisymmetric model with circular symmetry was used to produce $4 \mathrm{D}$ results. All material properties required were already available within the standard software library. Element size was set at $1 / 50^{\text {th }}$ of the driving frequency wavelength. Multi-parametric simulations were performed using Design 4 as the base architecture. The PZ54 ring centre hole diameter, glass thickness, glass diameter, and drive frequency were varied to determine if these changes resulted in a trend toward higher acoustic pressures.

For each modified variable, all other design parameters remained constant using the values stated in Table 1. The range of variables and their respective step size are shown in Table 3. The transducer was driven using a $100 \mathrm{~V}_{\mathrm{pp}}, 630 \mathrm{kHz}, 5$-cycle sine burst as determined by the peak frequency from the pulse-echo measurements (Section 2.3.1). Output data from PZFlex were further processed in MATLAB ${ }^{\circledR}$ R2014a (MathWorks, Natick, MA, USA). Spline and colour interpolation were used to smooth the output plots from the multi-parametric simulations.

\subsection{Isostatic pressure simulations}

SolidWorks ${ }^{\circledR} 2014$ Premium (Dassault Systèmes, Vèlizy-Villacoublay, France) was used to evaluate the transducer materials' ability to handle isostatic pressures using the in-built simulation package. Material properties were obtained from the standard software library and from the literature for PZ54 and epoxy [21], [22]. A static simulation was performed with a mesh node length of $\leq 1.6 \mathrm{~mm}$ (point of result convergence). An isostatic pressure was applied to the front face of the device and the case outer diameter was set as the fixed geometry. The isostatic surface pressure was increased incrementally in the range $0.35-6.90 \mathrm{MPa}$ in $0.35 \mathrm{MPa}(50 \mathrm{psi})$ steps. This pressure range was chosen as it corresponds to pressures at which petrochemical and liquefied petroleum gas pipelines operate [23]. The step size allowed visualisation of the stress and deformation close to the point of failure. The Von Mises stress distribution and deformation patterns were recorded.

\section{$3 \quad$ Results \& Discussion}

\subsection{Design and fabrication}

Two issues were observed during prototype manufacture. First, concentrically aligning the glass and PZ54 ring was difficult when the epoxy was still in a fluid state. This was corrected by using polytetrafluoroethylene (PTFE) blocks to align the PZT ring in relation to glass using ink marking on the glass as a guide. PTFE is well known for its lack of adhesion. Second, air pockets were trapped between the glass 
and the PZ54. This was avoided by placing the stack in a vacuum at $500 \mathrm{~Pa}$ for

\subsection{Acoustic Characterisation}

Electrical impedance measurements on the completed ultrasound transducers showed $5-12$ peaks in the spectra (Figure 3), attributed to extraneous resonance modes. In all impedance measurements, a drop in electrical reflection coefficient magnitude was observed in the frequency range $150-210 \mathrm{kHz}$. For Design 1: $\delta=0.133$ at $163 \mathrm{kHz}$; Design 2: $\delta=0.216$ at $152 \mathrm{kHz}$; Design 3: $\delta=0.086$ at $208 \mathrm{kHz}$; and Design 4: $\delta=0.094$ at $210 \mathrm{kHz}$. Based on the widths of the PZ54 rings and the acoustic propagation properties, $\mathrm{N}_{\mathrm{P}}=2100 \mathrm{Hzm}^{-1}$, it was concluded that these frequencies corresponded to the radial oscillation modes.

In all measurements, the second lowest value for $\delta$ was observed at a higher frequency than the lowest value of $\delta$. For Design 1: $\delta=0.250$ at $367 \mathrm{kHz}$; Design 2: $\delta=0.358$ at $475 \mathrm{kHz}$; Design 3: $\delta=0.412$ at $611 \mathrm{kHz}$; and Design 4: $\delta=0.331$ at $634 \mathrm{kHz}$. Based on the thickness of the PZ54 ring and the acoustic propagation properties, $\mathrm{N}_{\mathrm{T}}=2000 \mathrm{~Hz} \mathrm{~m}^{-1}$, these frequencies were concluded to correspond to the thickness oscillation modes i.e., the thickness mode resonance frequencies producing the required longitudinal ultrasound waves. Two to five peaks were observed between these two modes, identified as harmonics of the radial mode and other artefacts.

When comparing the electrical impedance measurements (Figure 3, black line) with the pulse-echo measurements (grey line), a distinct correlation was observed. Peaks were observed at both the radial and thickness mode frequencies, in addition to those relating to the intermediate modes. These indicate that either electrical impedance spectroscopy or acoustic pulse-echo measurements can be used to determine the behaviour of glass-windowed ultrasound transducers in under $5 \mathrm{~min}$ and that the facilities to carry out both tests are not needed.

Table 2 shows the frequency characteristics obtained from the pulse-echo measurements using -3 and $-6 \mathrm{~dB}$ cut-offs. The values of $f_{p}$ are $110 \mathrm{kHz}$ apart from Designs $1\left(f_{p}=350 \mathrm{kHz}\right)$ and $2\left(f_{p}=460 \mathrm{kHz}\right)$ even though nominally identical PZ54 elements were used. As the structural differences between Design 3 and 4 are minimal, a smaller difference in $f_{p}$ of $15 \mathrm{kHz}$ was obtained.

Using a $-3 \mathrm{~dB}$ cut-off, $\mathrm{BW}$ was $>65 \%$ for all designs and using a $-6 \mathrm{~dB}$ cut-off $\mathrm{BW}$ was up to $97 \%$. $\mathrm{Q}_{\mathrm{m}}$ was in the range $0.59-0.81$. In comparison, a commercially available single-element, air-backed, ultrasound transducer with a $500 \mathrm{kHz}$ centre frequency has a $-6 \mathrm{~dB}$ bandwidth of $61.6 \%$ and $\mathrm{Q}_{\mathrm{m}}$ of 0.61 [24].

The acoustic output power and pressure of the devices were also measured. Figure 4 shows acoustic power output as a function of waveform generator voltage, measured using a radiation force balance. Whilst Designs 3 and 4 were significantly smaller, they were both able to produce over $4 \mathrm{~W}$ of acoustic power. In contrast, Designs 1 and 2 were able to produce only approximately $2 \mathrm{~W}$ before the thickness mode expansion resulted in the PZT tensile stress reaching its limit. This issue may be solved by prestressing the elements [25]. A secondary limitation of this architecture was the buildup of heat. At $1 \mathrm{~W}$ output power, generated with a continuous wave at the peak frequency for each transducer for $60 \mathrm{~s}$ the region of the case with the highest temperature increased to $78 \pm 15^{\circ} \mathrm{C}$ for Designs 1 and 2 and to $88 \pm 10^{\circ} \mathrm{C}$ for Designs 3 and 4 . The difference in temperature between the case and glass surface was within the $\pm 2{ }^{\circ} \mathrm{C}$ error of the temperature gauge. 
Figure 5A shows the pressure values calculated using Eq. 4. Design 1 produced the lowest acoustic pressure as a function of drive voltage and Design 2 produced the highest acoustic pressure. These results are in good agreement with the simulation data indicating that conversion from power to pressure is a valid operation. The only design for which correlation is poor is Design 1 . This may be due to areas of adhesion failure between the glass disc and PZ54 ring resulting in a smaller than predicted cross-sectional area of maximum pressure closest to the transducer propagation face and hence increasing the derived acoustic pressure, based on Eq. 5.

Acoustic field scans were compared to simulations to validate the ability to predict the acoustic propagation pattern accurately (Fig. 6). The facial cross-sectional scans are able to differentiate the PZ54 ring and aluminium casing (Fig. 6 F1 - 4). In addition, concentric rings of higher and lower pressures with a peak directly in the centre are observed. This indicates that the glass may be oscillating like a diaphragm. In addition, the distance between these rings corresponds with the wavelength at the driving frequency.

Panels S1 - S4 (Fig. 6) show the simulated acoustic pressure profile for the different designs. It can be seen that completely different pressure fields are produced, depending on the design, with acoustic foci of different sizes at different locations. These variations may also be attributed partly to the different driving frequencies. Comparing the profiles to those measured experimentally, similar results were obtained. It is paramount to interpret the profile more than the position of colours as, due to unavoidable experimental misalignment $\left(<1^{\circ}\right)$, measurements were performed off plane, as a result altering the measured location of maxima. The experimental scan step size resulted in $6-9$ samples within the smallest $-6 \mathrm{~dB}$ profile. Reducing the step size may increase the acoustic profile in correspondence with the simulations.

Figure 7 shows the transient response of each design at the acoustic focus when driven with a 5-cycle sine wave burst. Ringing was observed in all designs except Design 1 which exhibits damped properties, with a $-20 \mathrm{~dB}$ ring-down period of only two cycles. Ring-down durations of 6 cycles for Design 2 and 12 cycles for Designs 3 and 4 were observed. These results contrast with the expected measurements of BW and $\mathrm{Q}_{\mathrm{m}}$ as, with large bandwidths and low $\mathrm{Q}_{\mathrm{m}}$, minimal ringing is expected. Here reduced ringing is observed, indicating damping. This may be due to the air-backing and increased isolation from the aluminium casing via 2.25 or $3.25 \mathrm{~mm}$ of epoxy. In Design 1, the glass is in direct contact with the aluminium case, which may increase damping and reduce ringing.

For all designs, subsequent signals were observed following ring-down. This is clearest in Design 1 (Fig. 7, red arrow). Increasing and decreasing the number of drive cycles did not change the number of cycles in the subsequent signals. Moving the hydrophone further from the transducer did not move the temporal location of the signals. This indicates that these signals were generated within the ultrasound transducers as a result of their architecture.

The Fourier spectra show a distinct peak at the drive frequency indicating acoustic fidelity. With increased ringing, increased harmonic activity was observed between $1-2 \mathrm{MHz}$, i.e., close to the $3^{\text {rd }}$ harmonic.

\subsection{Acoustic Simulations}

Figure 8 shows the simulated peak-to-peak axial acoustic pressure at the centre of each design as a function of several variables, based on Design 4. As the centre hole diameter is increased (Figure 8A) the furthest acoustic pressure maxima moves closer to the face of the transducer. For diameters between 7.5 and $11.5 \mathrm{~mm}$, a new acoustic 
focus starts to form at approximately $60 \mathrm{~mm}$ from the transducer face. When the diameter is $14 \mathrm{~mm}$, an area of high acoustic pressure $50 \mathrm{~mm}$ in length is observed, starting from the transducer surface. Varying the glass thickness (Figure 8B) results in the expected outcome: the maximum acoustic pressure is observed in the thickness range $2-4 \mathrm{~mm}$, corresponding approximately to $1 / 4 \lambda$. This agrees with observation of maximum sensitivity from the experimental pulse-echo measurements. The highest acoustic pressure was observed with a glass radius of $14.5 \mathrm{~mm}, 0.5 \mathrm{~mm}$ smaller than the outer radius of the PZ54 ring (Figure 8C). Varying the driving frequency (Figure 8D) gives the predictable results that as the drive frequency reaches the resonance frequency of the device the acoustic pressure is maximized and an area of high acoustic pressure is formed furthest from the transducer surface. The simulations show the furthest and largest area of high acoustic pressure formed at approximately $600 \mathrm{kHz}$.

The agreement between the simulated and experimentally measured values indicates that this transducer architecture can be simulated and thus that simulations can be used to determine the optimal material dimensions (i.e., glass thickness and mounting location, and PZ54 thickness, and inner and outer diameters) and drive frequency. All 480 simulations took 160 hours to solve, indicating an average simulation time of 20 min. However this varies with transducer frequency. Reducing the drive frequency increases the element size and as a result reduces the required simulation time. Hence, at lower frequencies $(\sim 600 \mathrm{kHz})$, a simulation took approximately 10 minutes whereas at higher frequencies $(\sim 1 \mathrm{MHz})$ a simulation took over 40 minutes. Subsequently, compiling, processing and plotting each dataset using an automated script took approximately $30 \mathrm{~s}$.

\subsection{Stress and Deflection}

Isostatic pressure simulations (Fig. 9) show that the different designs result in different stress distribution profiles. Isostatic pressure applied to the front face of the device is shown with red arrows in Figure 9:1a - 4a. The case outer diameter was set as the fixed geometry, shown as green arrows in Figure 9:1a - 4a. The information gained from these simulations is important in applications where isostatic pressures up to $9.7 \mathrm{MPa}$ (1400 psi) are applied, such as in the measurement of flow in highpressure pipes [23].

Depending on the glass mounting location, the area of highest stress was found to vary (Fig. 9:1b-4b). The largest stress distribution was observed with Design 2. The primary area of stress was in the glass in Designs 1 and 2, whereas the stress was distributed at the inner lower edge of the piezoelectric element in Designs 3 and 4. As expected, maximum deflection was observed at the centre of the transducers near the glass window. In Designs 1 and 2, deflection occurred primarily in the glass (Fig. 9:1c-4c red and yellow regions). In Designs 3 and 4, where the window is smaller, the area of maximum deflection was found to be in the piezoelectric element. The point of failure $(\mathrm{PoF})$ was defined as the point at which the material stress surpasses the material tensile modulus of $48 \mathrm{MPa}$ for fused quartz [26], and $45 \mathrm{MPa}$ for PZT [27]. In the transducer architectures considered here, either the glass or PZ54 reached the failure point first (Fig. 10) with the epoxy failing to reach the failure point because of its high elasticity. It should be noted that these simulations do not take into account the bonding strength between the epoxy, the PZT ring, and the metal casing, as this may be the first point of failure. 
Design 1 was the weakest, showing glass failure at $\sim 2.1 \mathrm{MPa}$. This is due to the higher concentration of stress in a smaller area, and the larger amount of deflection. The PZT failed in Designs 3 and 4 at $\sim 3.5 \mathrm{MPa}$. However, this may not result in an operational failure as PZT is a ceramic and only a small portion of the PZT may be damaged allowing continued operation. Design 2 proved to be the strongest, with glass failure at $\sim 4.8 \mathrm{MPa}$. If the $\mathrm{PoF}$ is considered the point at which the glass fails, since this will certainly result in operational failure, then Designs 3 and 4 are considered the strongest, with failure observed at $\sim 5.5 \mathrm{MPa}$. All designs required $<50 \mu \mathrm{m}$ of deformation (Fig. 10B) for failure to occur. If it was possible, redesigning the transducers to be more elastic or distributing the stress over a larger area would increase the pressure required to reach $\mathrm{PoF}$.

\section{Conclusions}

A transducer architecture combining a central $10-20 \mathrm{~mm}$ diameter quartz glass window has been described, with four design variations operating at centre frequencies in the range $350<f_{c}<630 \mathrm{kHz}$ constructed and simulated. The design variations were the dimensions of the piezoelectric ring, the diameter and thickness of the glass, and the location of attachment of the glass disc. Based on the design variations, the architecture that has been described resulted in transducers with $-6 \mathrm{~dB}$ bandwidths in the range $87-97 \%$, acoustic output power of more than $1 \mathrm{~W}$, and acoustic pressure of more than $1 \mathrm{MPa}$ peak-to-peak.

600 The acoustic fields generated by the transducers were compared with simulations 601 based on finite element analysis. The acoustic simulations were able to predict the behaviour of the fabricated devices. A total of 480 simulations with varying material dimensions indicated that design variations modify the emitted acoustic profile 604 nonlinearly.

605 Isostatic pressure simulations indicated that specific design variations of this architecture could sustain isostatic pressures up to $4.8 \mathrm{MPa}$.

609 This research was supported by Helse Vest and MedViz (http://medviz.uib.no/), a 610 research consortium from Haukeland University Hospital, University of Bergen and 611 Christian Michelsen Research AS. 


\section{Tables}

\begin{tabular}{|l|l|l|l|l|l|l|l|l|}
\hline \multirow{2}{*}{ Design } & \multicolumn{9}{l}{ PZT } & Glass & Case & \\
\cline { 2 - 9 } & ID & OD & TH & OD & TH & ID & OD & H \\
\hline \hline 1 & 20 & 40 & 5 & 50 & 2 & 44.5 & 50 & 50 \\
\hline 2 & 20 & 40 & 5 & 40 & 4 & 44.5 & 50 & 50 \\
\hline 3 & 10 & 25 & 4 & 25 & 3 & 31.5 & 38 & 50 \\
\hline 4 & 10 & 25 & 4 & 30 & 3 & 31.5 & 38 & 50 \\
\hline
\end{tabular}

614 Table 1: Glass-windowed ultrasound transducer dimensions. All units are in $\mathrm{mm}$. 615 (Key: ID - inner diameter, OD - outer diameter, TH - thickness, $\mathrm{H}$ - height)

616 


\begin{tabular}{|c|c|c|c|c|c|c|c|c|c|c|c|c|c|}
\hline \multirow{2}{*}{ Design } & \multirow{2}{*}{$f_{\mathrm{p}}[\mathrm{kHz}]$} & \multicolumn{2}{|c|}{$f_{\mathrm{c}}[\mathrm{kHz}]$} & \multicolumn{2}{|c|}{$f_{1}[\mathrm{kHz}]$} & \multicolumn{2}{|c|}{$f_{\mathrm{u}}[\mathrm{kHz}]$} & \multicolumn{2}{|c|}{$\mathrm{BW}[\mathrm{kHz}]$} & \multicolumn{2}{|c|}{$\mathrm{BW}[\%]$} & \multicolumn{2}{|l|}{$Q_{\mathrm{m}}$} \\
\hline & & $-3 \mathrm{~dB}$ & $-6 \mathrm{~dB}$ & $-3 \mathrm{~dB}$ & $-6 \mathrm{~dB}$ & $-3 \mathrm{~dB}$ & $-6 \mathrm{~dB}$ & $-3 \mathrm{~dB}$ & $-6 \mathrm{~dB}$ & $-3 \mathrm{~dB}$ & $-6 \mathrm{~dB}$ & $-3 \mathrm{~dB}$ & $-6 \mathrm{~dB}$ \\
\hline 1 & 350 & 436 & 465 & 294 & 240 & 577 & 689 & 283 & 449 & 65 & 97 & 0.81 & 1.28 \\
\hline 2 & 460 & 419 & 430 & 258 & 232 & 580 & 627 & 322 & 395 & 77 & 92 & 0.70 & 0.86 \\
\hline 3 & 615 & 550 & 547 & 366 & 308 & 734 & 785 & 368 & 477 & 67 & 87 & 0.60 & 0.78 \\
\hline 4 & 630 & 549 & 539 & 362 & 297 & 735 & 780 & 373 & 483 & 68 & 90 & 0.59 & 0.77 \\
\hline
\end{tabular}

Table 2: Acoustic properties of transducer designs calculated from pulse-echo measurements where $f_{\mathrm{p}}$ is the peak frequency, $f_{\mathrm{c}}$ is the centre frequency, $f_{1}$ is the lower cut-off frequency, $f_{\mathrm{u}}$ is the upper cut-off frequency, BW is the bandwidth, and $Q_{\mathrm{m}}$ is the mechanical quality factor. 


\begin{tabular}{|c|c|c|c|c|}
\hline Variable & Lower value & Upper value & Step size & $\begin{array}{l}\text { Number } \\
\text { of steps }\end{array}$ \\
\hline PZT hole diameter & $2.0 \mathrm{~mm}$ & $14.0 \mathrm{~mm}$ & $0.1 \mathrm{~mm}$ & \multirow{4}{*}{120} \\
\hline Glass thickness & $1.0 \mathrm{~mm}$ & $6.0 \mathrm{~mm}$ & $415 \mu \mathrm{m}$ & \\
\hline Glass radius & $12.6 \mathrm{~mm}$ & $15.5 \mathrm{~mm}$ & $242 \mu \mathrm{m}$ & \\
\hline Drive frequency & $300 \mathrm{kHz}$ & $1.0 \mathrm{MHz}$ & $5.8 \mathrm{kHz}$ & \\
\hline
\end{tabular}

Table 3. Variables, their ranges, and step sizes used to simulate the acoustic output pressure of the glass windowed ultrasound transducers. 


\section{Figures}

Figure 1: (A) Graphical representation of designs evaluated with cross-section illustrations depicting component location and geometry. (B) Schematic depicting labels for transducer geometry.

Figure 2: Acoustic power output from the four different designs as a function of peak-topeak waveform generator voltage amplitude measured using an acoustic radiation force balance. The tapering off at high acoustic power levels indicates the tensile stress in the PZT is reaching its tensile strength.

Figure 3: Electrical impedance reflection coefficient (left axis, black line) and normalised frequency sensitivity (right axis, grey line) of devices. A lower electrical reflection coefficient is considered optimal whilst a large magnitude frequency sensitivity indicates optimal working frequency. A direct correlation between electrical impedance reflection coefficient and frequency sensitivity can be seen.

Figure 4: Acoustic power output from the four different designs as a function of peak-topeak waveform generator voltage amplitude measured using an acoustic radiation force balance. The tapering off at high acoustic power levels indicates the tensile stress in the PZT is reaching its tensile strength.

Figure 5: Measured and simulated acoustic pressures in focal zone of the four designs as a function of peak-to-peak waveform generator voltage amplitude. A direct correlation can be seen between the experimental measurements and simulations.

Figure 6: Field scans and corresponding simulations of a 5-cycle pulse from the four different transducers designs indicating the acoustic pressure profile. F1 - F4 show the measured profile approximately $1 \mathrm{~mm}$ from the face of the transducer $(x-y)$. S1 - S4 show the simulated data in the axial direction $(z-y)$, and M1 - M4 show the equivalent measured data. All frames are identical scale, where the scale bar represents $10 \mathrm{~mm}$. Measurements were performed using a $500 \mu \mathrm{m}$ step size, where as simulation were performed using a $1 / 50$ resolution.

Figure 7: Transient response and corresponding frequency spectra of the four transducer designs. The distance (d) between hydrophone and transducer is shown in the respective panel. Red arrow and indicate region show additional acoustic activity generated from the ultrasound transducer. Design 1 shows minimal ringing whereas Designs $2-4$ show increased ringing, which corresponds with higher harmonic content.

Figure 8: Multi-parametric simulations comparing the axial peak-peak acoustic pressure as a function of (A) central hole diameter, (B) glass thickness, (C) glass radius, and (D) driving frequency. Acoustic profiles were simulated for Design 4, using a 5-cycle sinewave burst as the electrical input. A complex interaction can be seen for changes in construction geometry. 
Figure 9: Isostatic stress simulation setup and results. (a) Mesh, (b) stress, and (c) deflection distributions are shown in the four transducer designs when an isostatic load is applied to the front face. Maximum deflection is observed in the centre of the device. Peak stress is observed in the centre of the glass for Designs 1 and 2, and in the PZT for Designs 3 and 4.

Figure 10: Simulation results indicating peak Von Mises stress and deformation in the four designs as a function of isostatic loading on the front face. Gray and black dots indicate points of failure and which material surpasses its tensile modulus first. 


\section{Bibliography}

[1] G. Brodie, Y. Qiu, and S. Cochran, "Optically transparent piezoelectric transducer for ultrasonic particle manipulation.," IEEE Trans. Ultrason. Ferroelectr. Freq. Control, vol. 61, no. 3, pp. $389-391,2014$.

[2] O. Moumeni, O. Hamdaoui, and C. Pétrier, "Sonochemical degradation of malachite green in water," Chem. Eng. Process. Process Intensif., vol. 62, pp. $47-$ 53, 2012.

[3] A. D. Kersey, "Optical Fiber Sensors for Permanent Downwell Monitoring Applications in the Oil and Gas Industry," IEICE Trans. Electron., vol. E83-C, no. 3, pp. 400-404, 2000.

[4] Y. Yan, "Mass flow measurement of bulk solids in pneumatic pipelines," Meas.Sci. \& Tech., vol. 7, no. 12, pp. 1687-1706, Dec. 1996.

[5] B. Verhaagen and D. Fernández Rivas, "Measuring cavitation and its cleaning effect.," Ultrason. Sonochem., 2015.

[6] R. C. Baker, "Ultrasonic Flowmeters," in Flow Measurement Handbook: Industrial Designs, Operating Principles, Performance, and Applications, Cambridge: Cambridge University Press, 2000, pp. 312-356.

[7] X. Chen, R. S. Leow, Y. Hu, J. M. F. Wan, and A. C. H. Yu, "Single-site sonoporation disrupts actin cytoskeleton organization.," J. R. Soc. Interface, vol. 11, no. 95, p. 20140071, Jun. 2014.

[8] S. Kotopoulis, A. Delalande, M. Popa, V. Mamaeva, G. Dimcevski, O. H. Gilja, M. Postema, B. T. B. T. Gjertsen, E. Mc Cormack, and E. McCormack, "Sonoporation-enhanced chemotherapy significantly reduces primary tumour burden in an orthotopic pancreatic cancer xenograft," Mol. Im. Biol., vol. 16, no. 1, pp. 53-62, 2014.

[9] S. Kotopoulis and M. Postema, "Microfoam formation in a capillary," Ultrasonics, vol. 50, no. 2, pp. 260-268, 2010.

[10] B. Gerold, I. Rachmilevitch, and P. Prentice, "Bifurcation of ensemble oscillations and acoustic emissions from early stage cavitation clouds in focused ultrasound," New J Phys, vol. 15, no. 3, p. 33044, 2013.

[11] B. Gerold, S. Kotopoulis, C. McDougall, D. McGloin, M. Postema, P. Prentice, and M. C., "Laser-nucleated acoustic cavitation in focused ultrasound," Rev. Sci. Instrum., vol. 82, no. 4, p. 44908, 2011.

[12] M. Domenjoud, M. Lematre, M. Gratton, M. Lethiecq, and L.-P. Tran-Huu-Hue, "Theoretical and experimental study of the electroacoustic behavior of lithium niobate under an initial mechanical stress.," IEEE Trans. Ultrason. Ferroelectr. Freq. Control, vol. 60, no. 10, pp. 2219-24, Oct. 2013.

[13] M. Postema, Fundamentals of medical ultrasonics. London: Spon Press, 2011.

[14] S. Kotopoulis, H. Wang, S. Cochran, and M. Postema, "Lithium niobate transducers for MRI-guided ultrasonic microsurgery," IEEE Trans. Ultrason. Ferroelectr. Freq. Control, vol. 58, no. 8, pp. 1570-1576, 2011.

[15] T. Yddal, S. Cochran, O. H. Gilja, M. Postema, and S. Kotopoulis, "Open-source, high-throughput ultrasound treatment chamber.," Biomed. Tech. (Berl)., vol. 60, no. 1, pp. 77-87, Feb. 2015.

[16] “ASTM Standard E1065," Standard Guide for Evaluating Characteristics of Ultrasonic Search Units. ASTM International, West Conshocken, PA, 2008. 
[17] K. Attenborough and M. Postema, "Waves and Sound," in Fundamentals of Medical Ultrasonics, M. Postema, Ed. Abingdon: Spon Press, 2011, p. 84.

[18] International Electrotechnical Commision, "Radiation force balances and performance requirements (IEC 61161)," 2013.

[19] F. Davidson, "Ultrasonic Power Balances," in Output Measurements for Medical Ultrasound, 1991, p. 87.

[20] National Physics Laboratory, "Radiation Force Measurements: Extrapolation Method," Best Practice Guide to Measurement of Acoustic Output Power (Measurement), 2010. [Online]. Available:

http://www.npl.co.uk/acoustics/ultrasonics/research/best-practice-guide-tomeasurement-of-acoustic-output-power-(measurement)/*/viewPage/5.

[21] M. Prudenziati and J. Hormadal, Eds., "Thick films based on ferroelectric inorganic compounds," in Printed Films: Materials Science and Applications in Sensors, Electronics and Photonics, Woodhead Publishing, 2012, p. 230.

[22] A. Bernassau and D. Hutson, "Characterisation of an epoxy filler for piezocomposite material compatible with microfabrication processes," Proc. IEEE Ultrason. Symp., pp. 62-65, 2008.

[23] W. L. L. Thomas O. Miesner, "Chapter 6: Petrochemical and LPG Pipeline Operations," in Oil \& Gas Pipelines in Nontechnical Language, PennWell Corporation, 2006, p. 110.

[24] O. Saito, Z. Wang, H. Mitsumura, T. Ogawa, Y. Iguchi, and M. Yokoyama, "Substantial fluctuation of acoustic intensity transmittance through a bonephantom plate and its equalization by modulation of ultrasound frequency.," Ultrasonics, vol. 59, pp. 94-101, May 2015.

[25] K. Adachi, I. Ogasawara, Y. Tamura, M. Makino, and N. Kato, "Influence of Static Prestress on the Characteristics of Bolt-Clamped Langevin-Type Transducers," Jpn. J. Appl. Phys., vol. 37, no. Part 1, No. 5B, pp. 2982-2987, May 1998.

[26] R. E. Bolz and G. Tuve, Eds., "Properties of clear fused quartz," in $C R C$ Handbook of Tables for Applied Engineering Science, New York: CRC Press, 1973, p. 187.

[27] S. R. Anton, A. Erturk, and D. Inman, "Bending strength of piezoelectric ceramics and single crystals for multifunctional load-bearing applications.," IEEE Trans. Ultrason. Ferroelectr. Freq. Control, vol. 59, no. 6, pp. 1085-1092, 2012. 
A

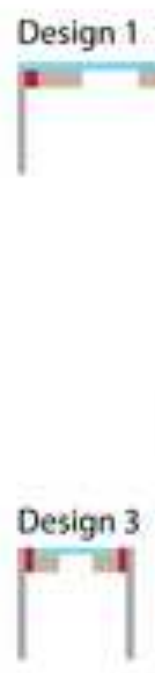

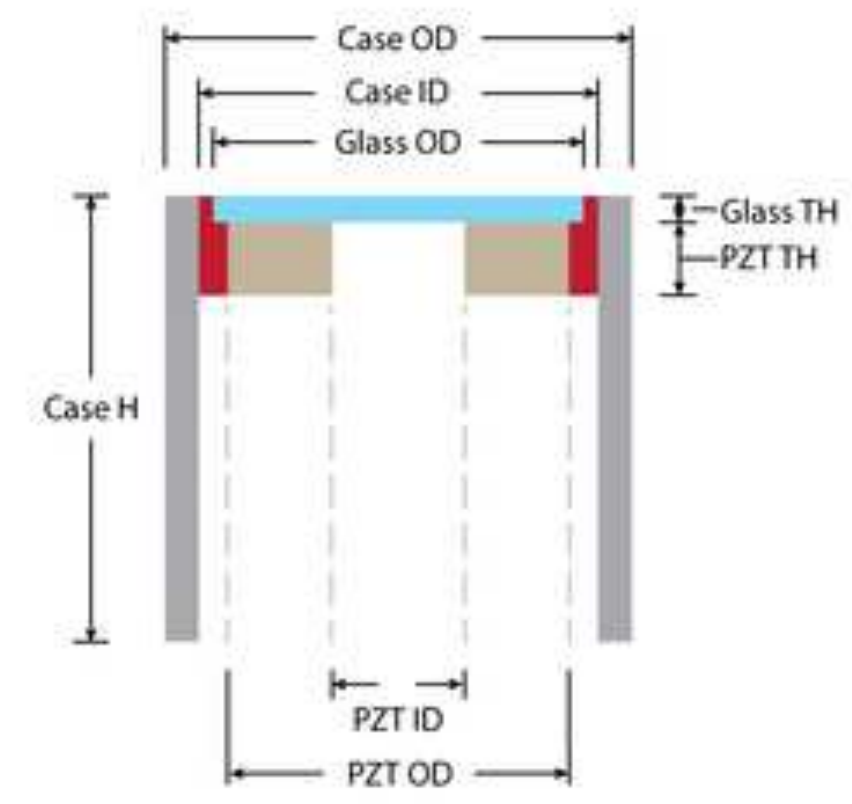

\section{Design 2}

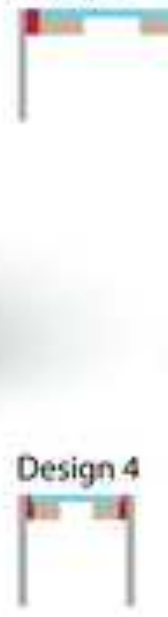

B

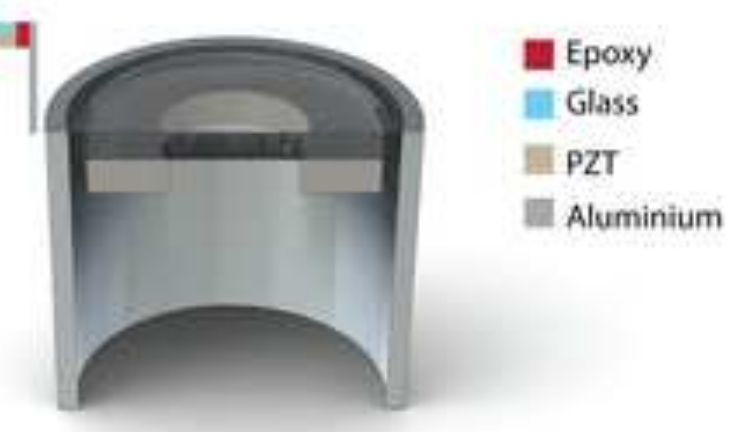

B
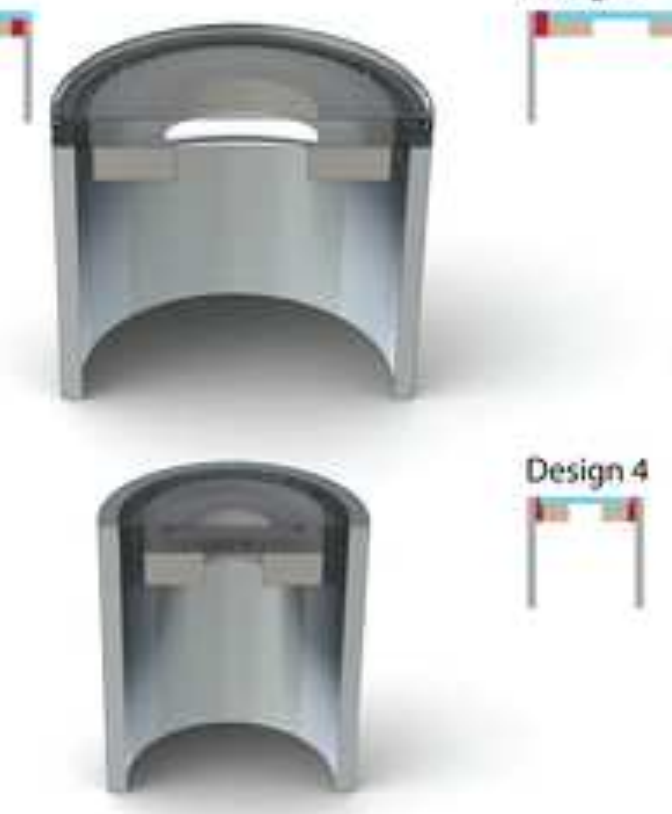

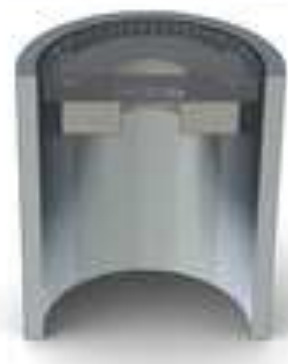




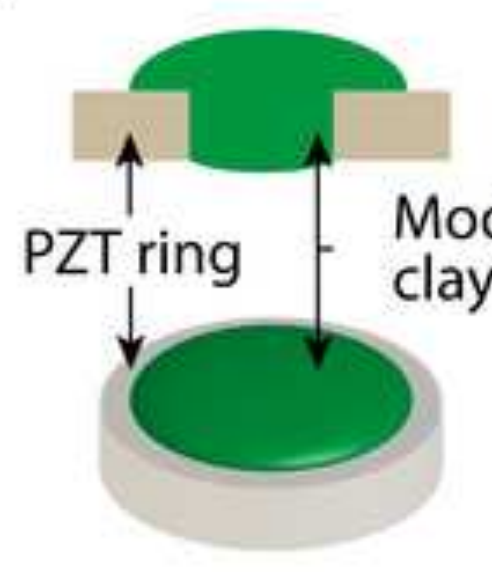

A
B

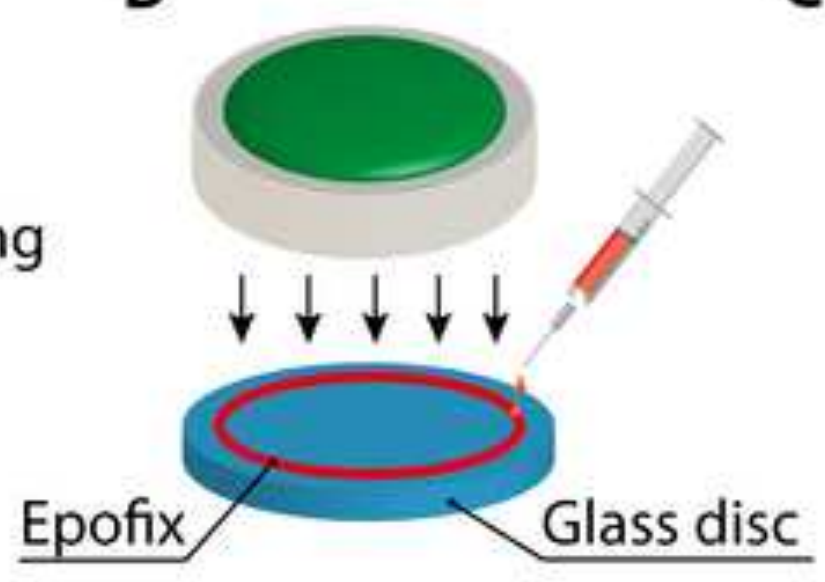

C Microcoaxial cable
D

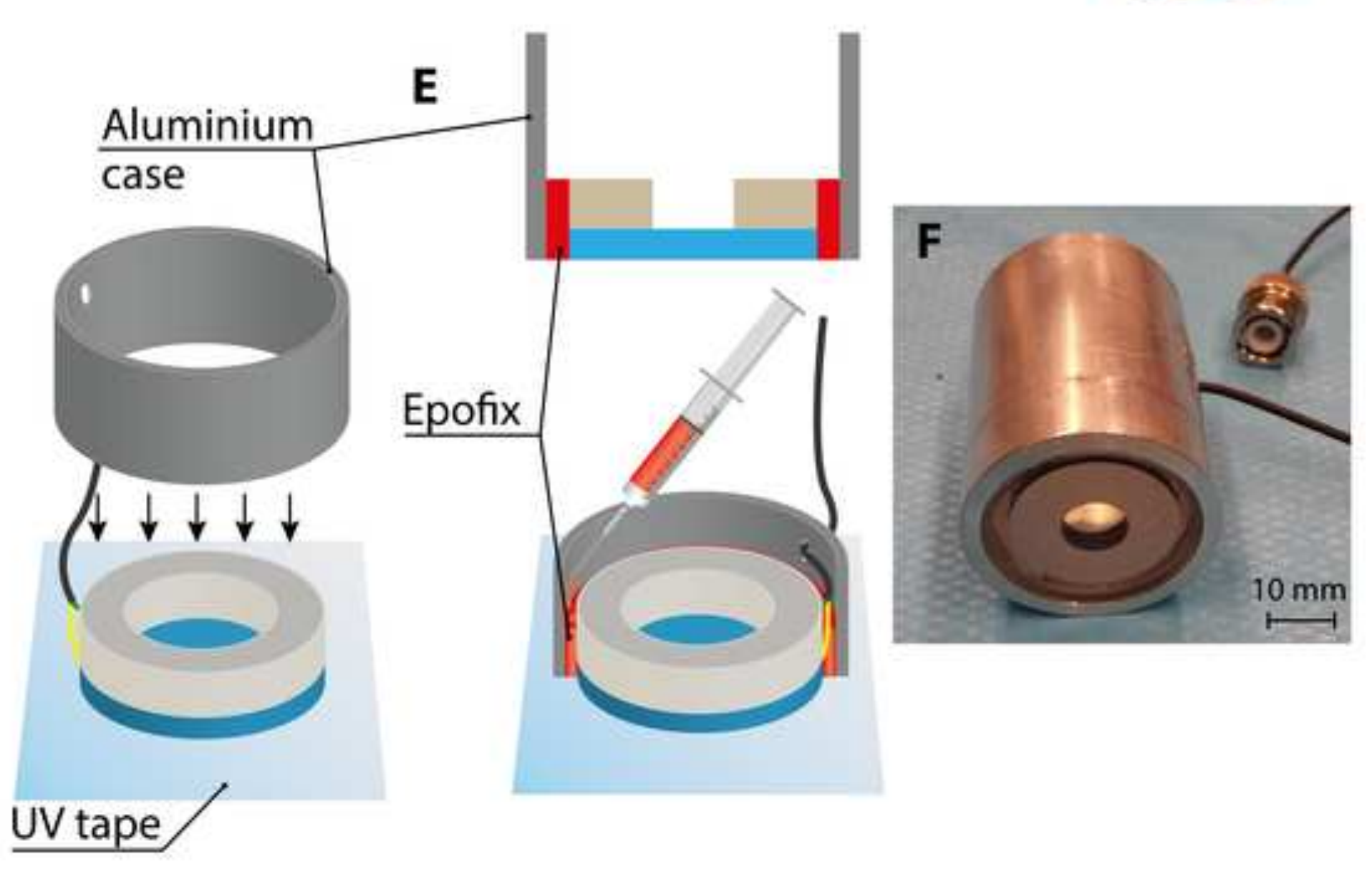



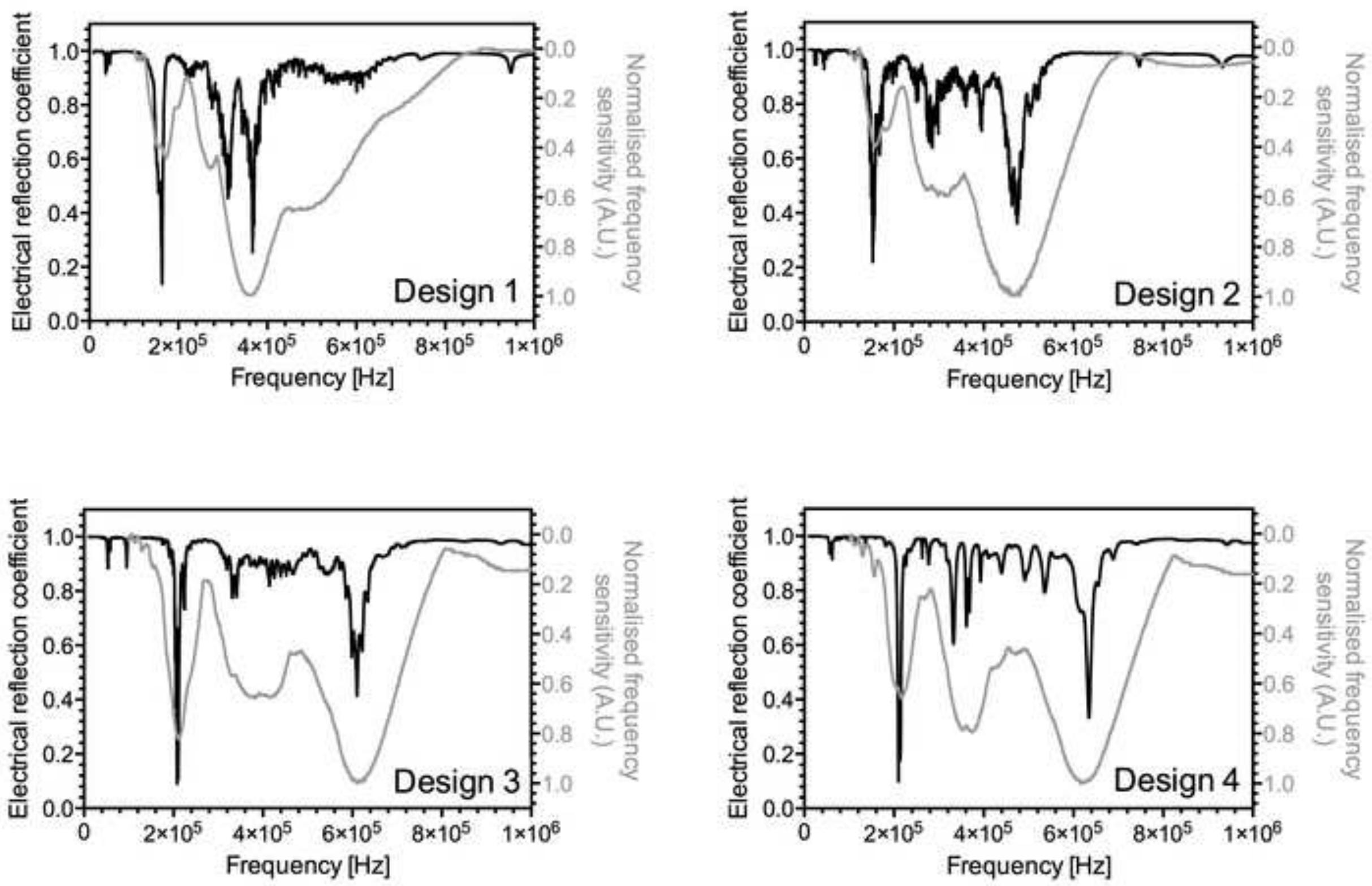


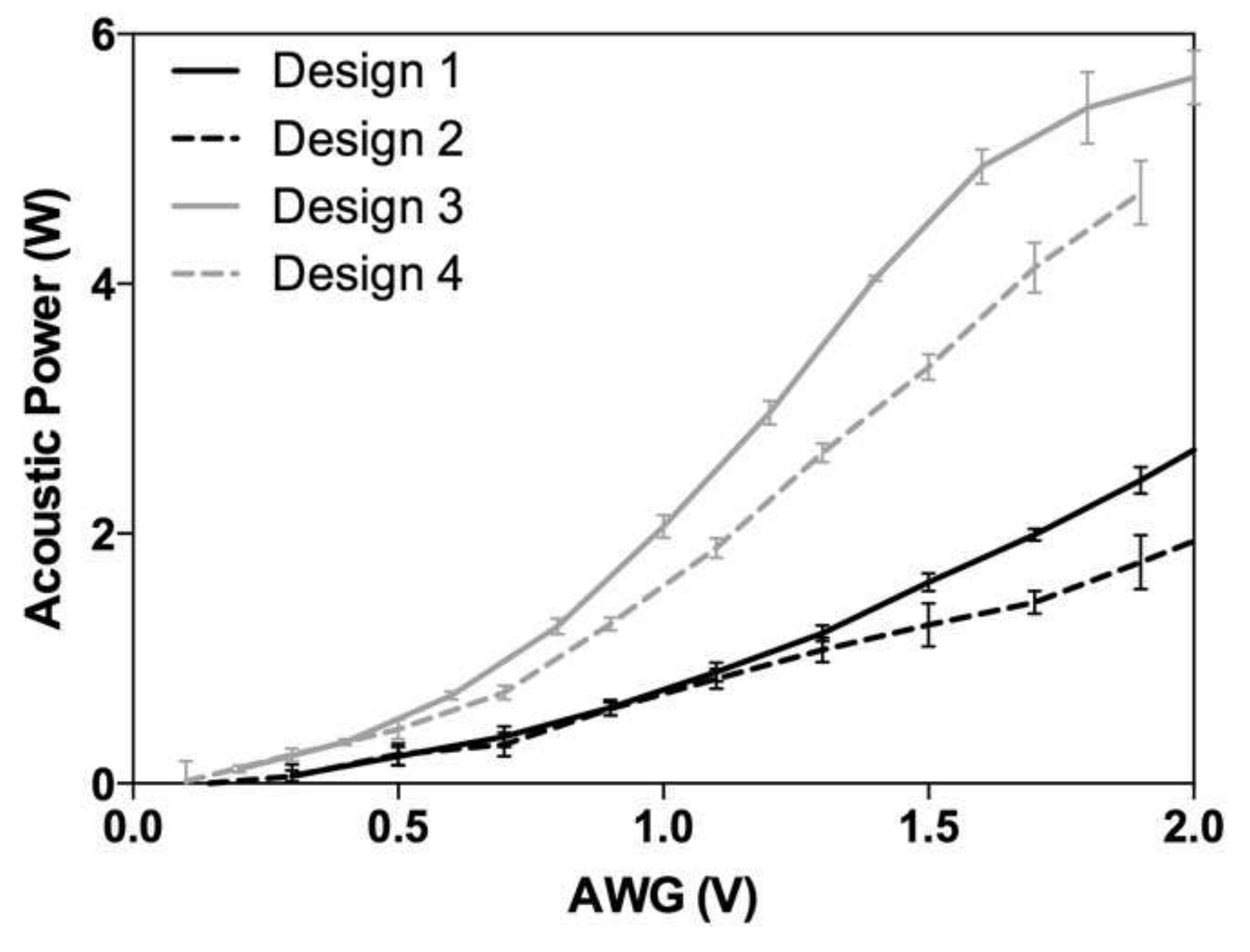


Acoustic Pressure

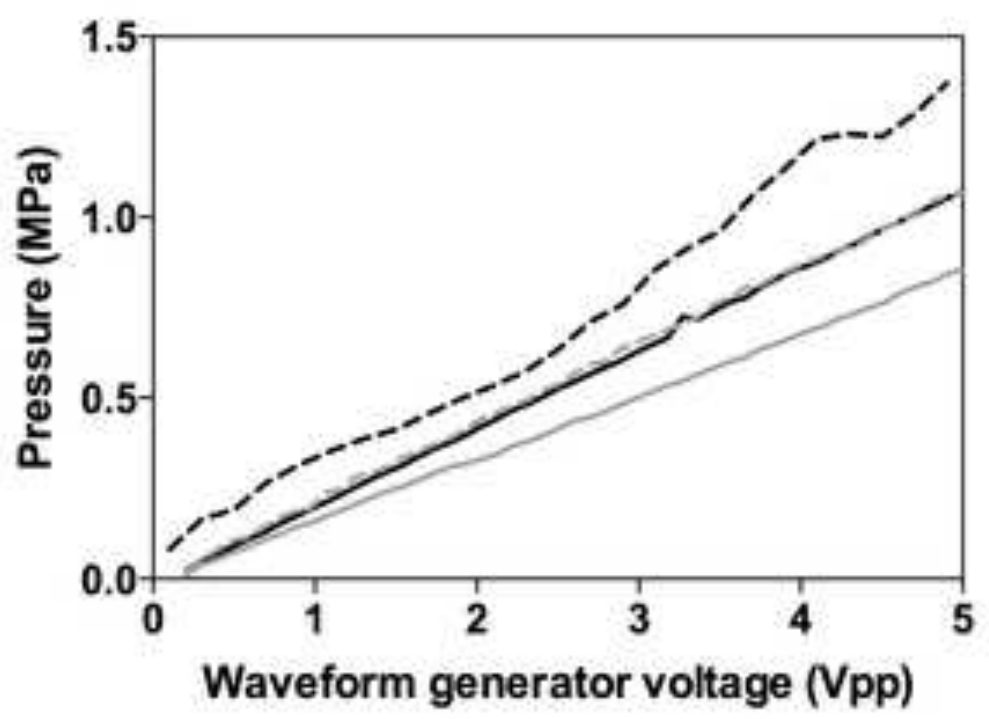

Simulated PMAX

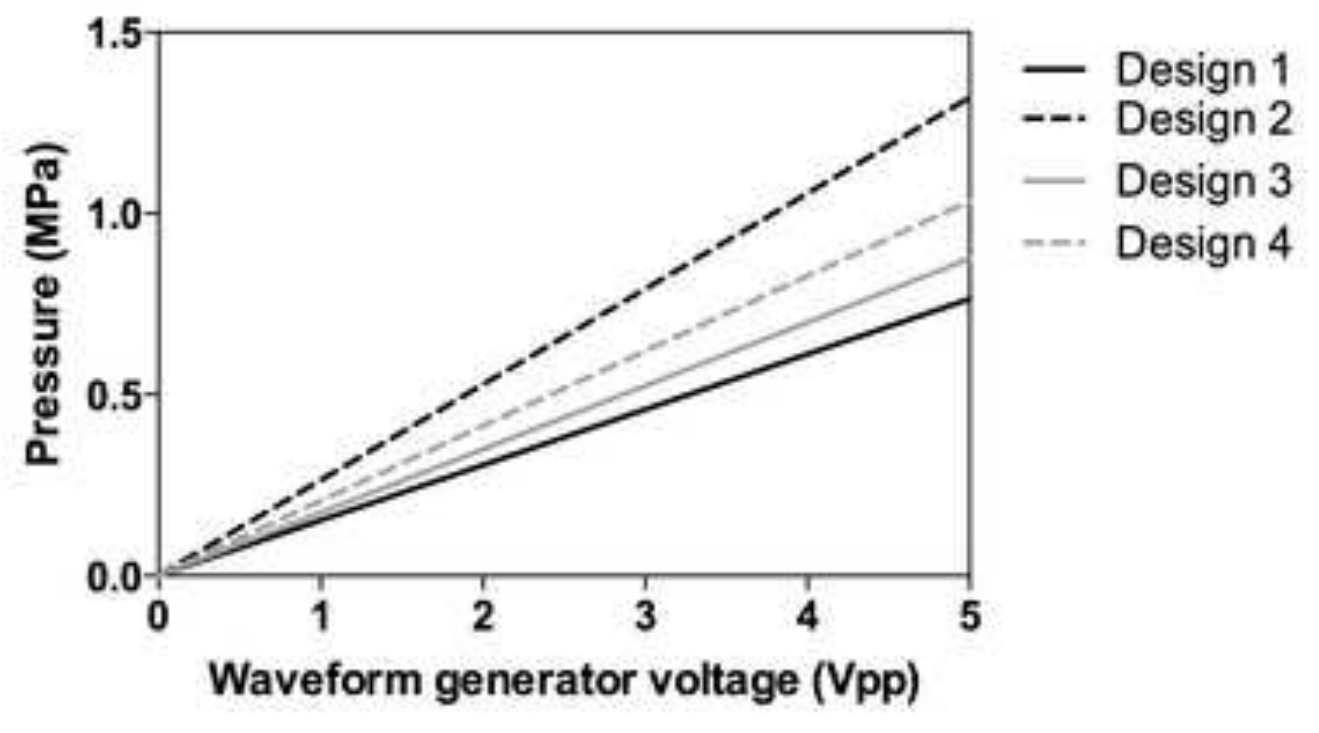




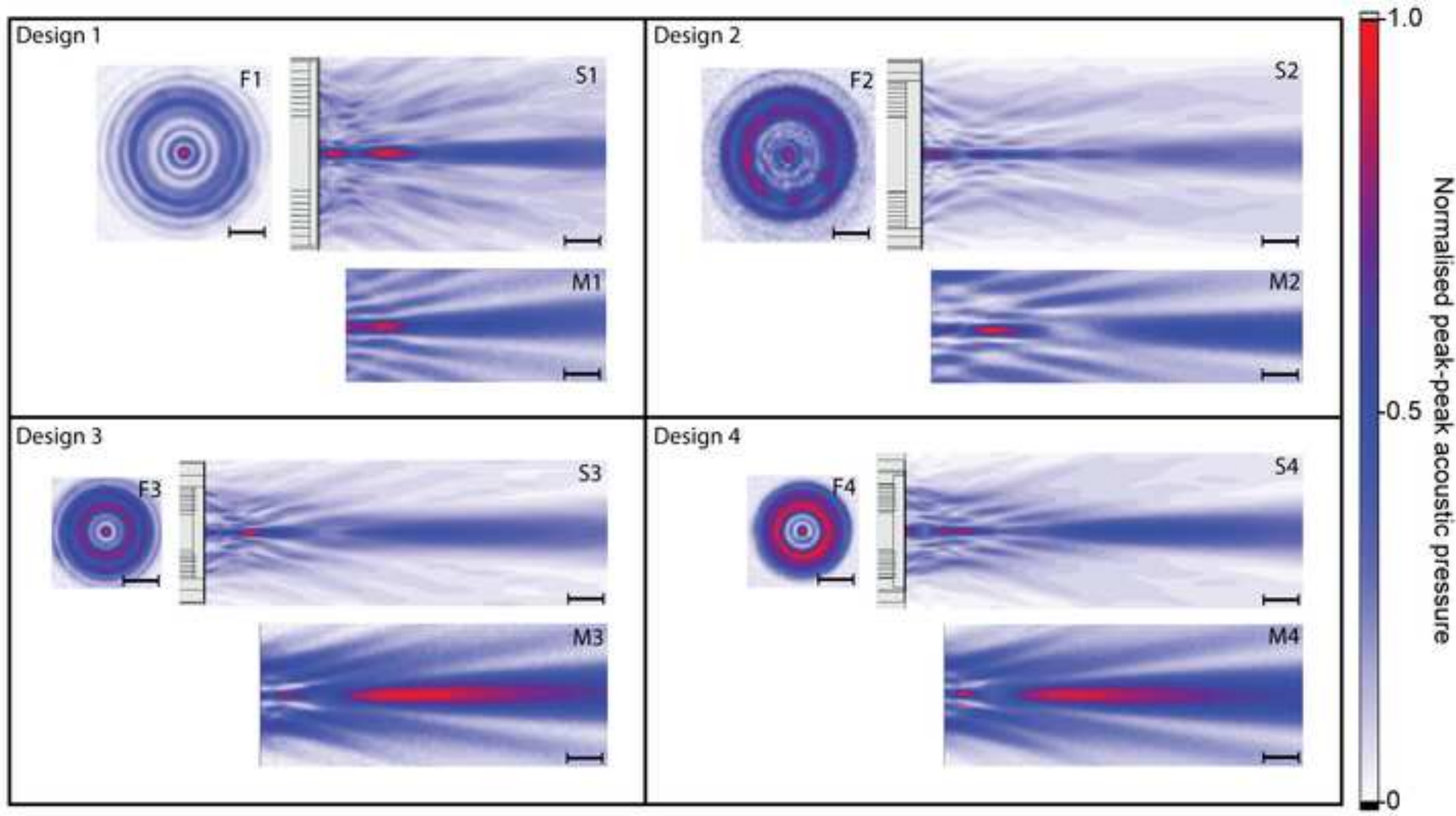


Transient response
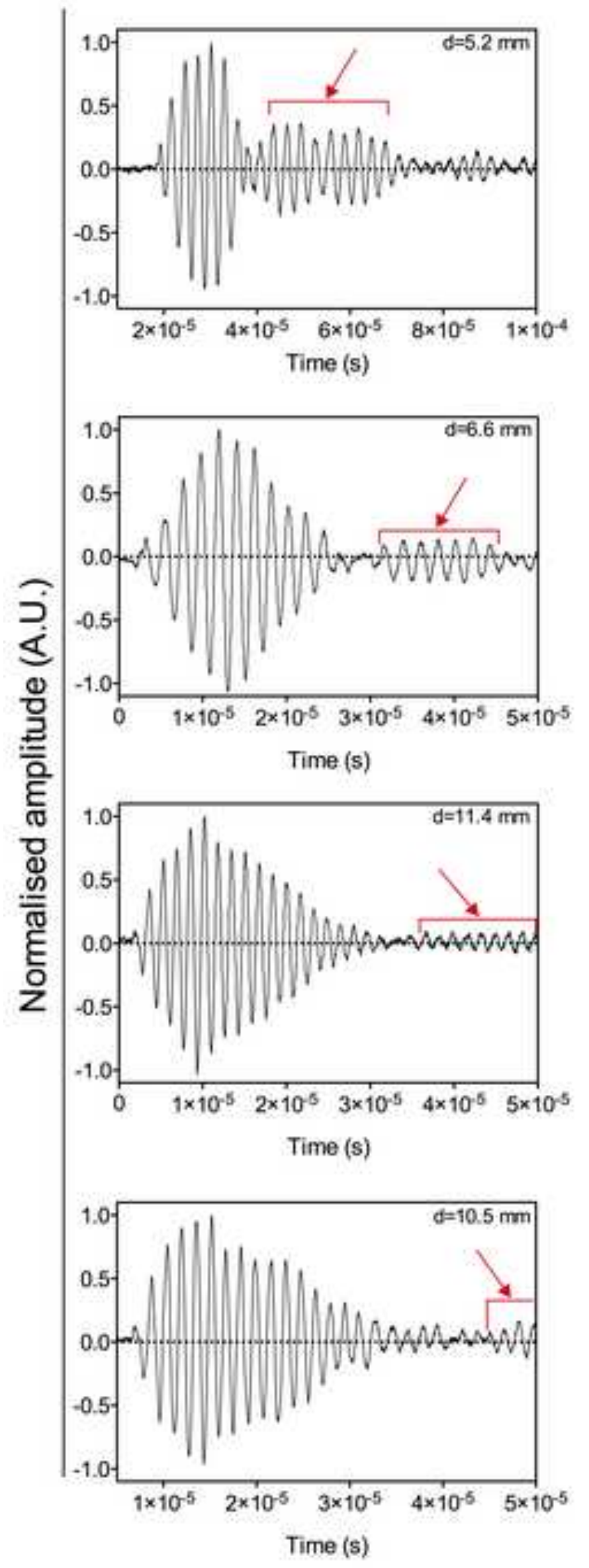

Time (s)

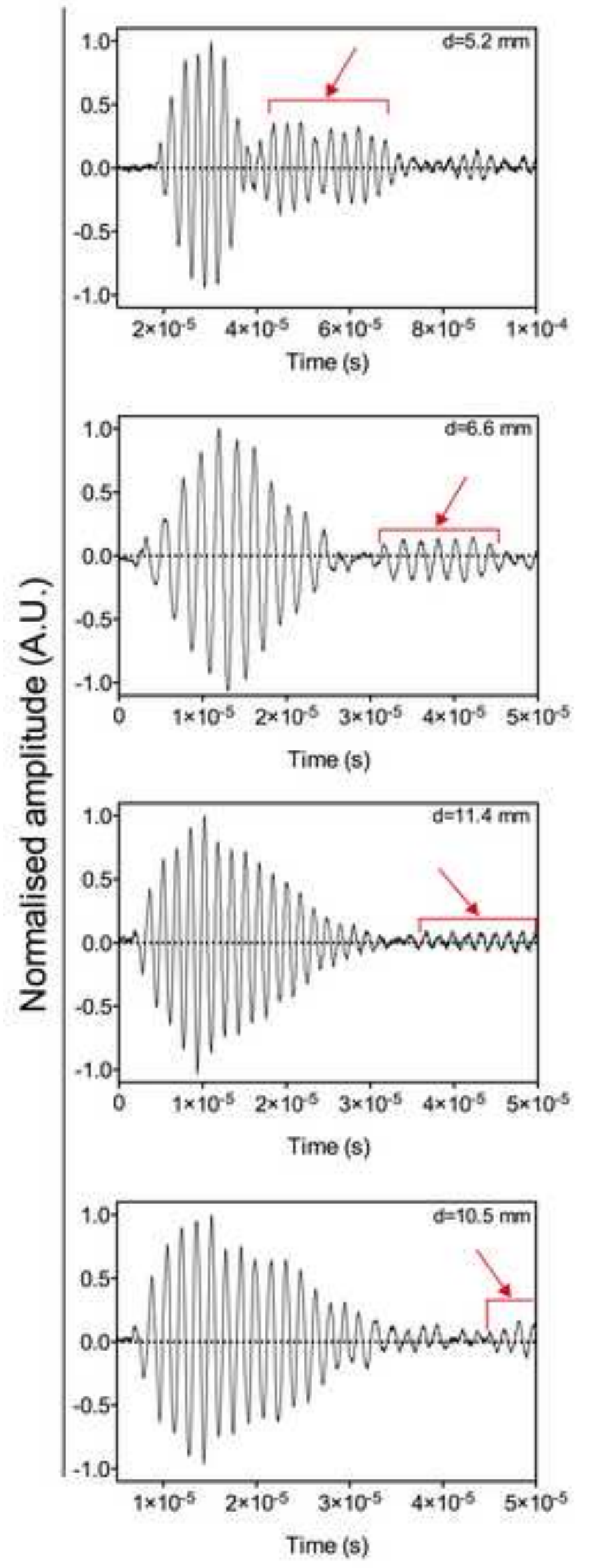

Time (s)

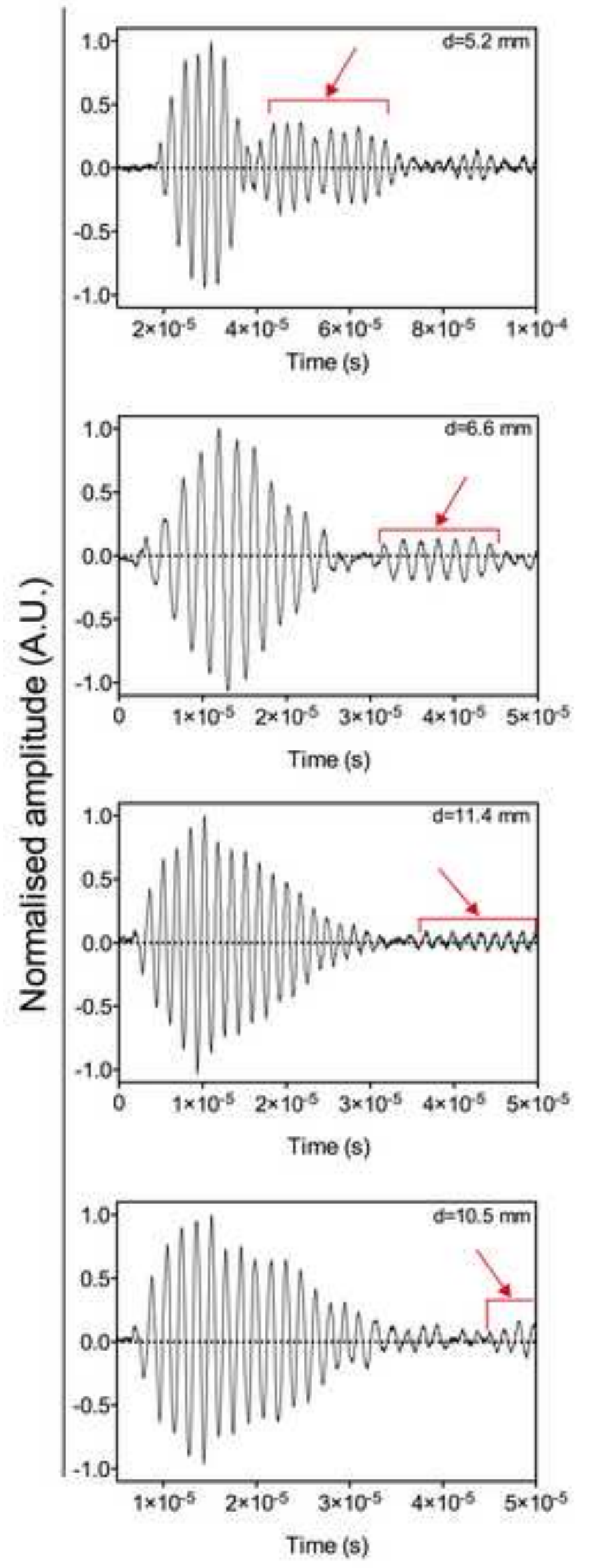

Frequency spectrum
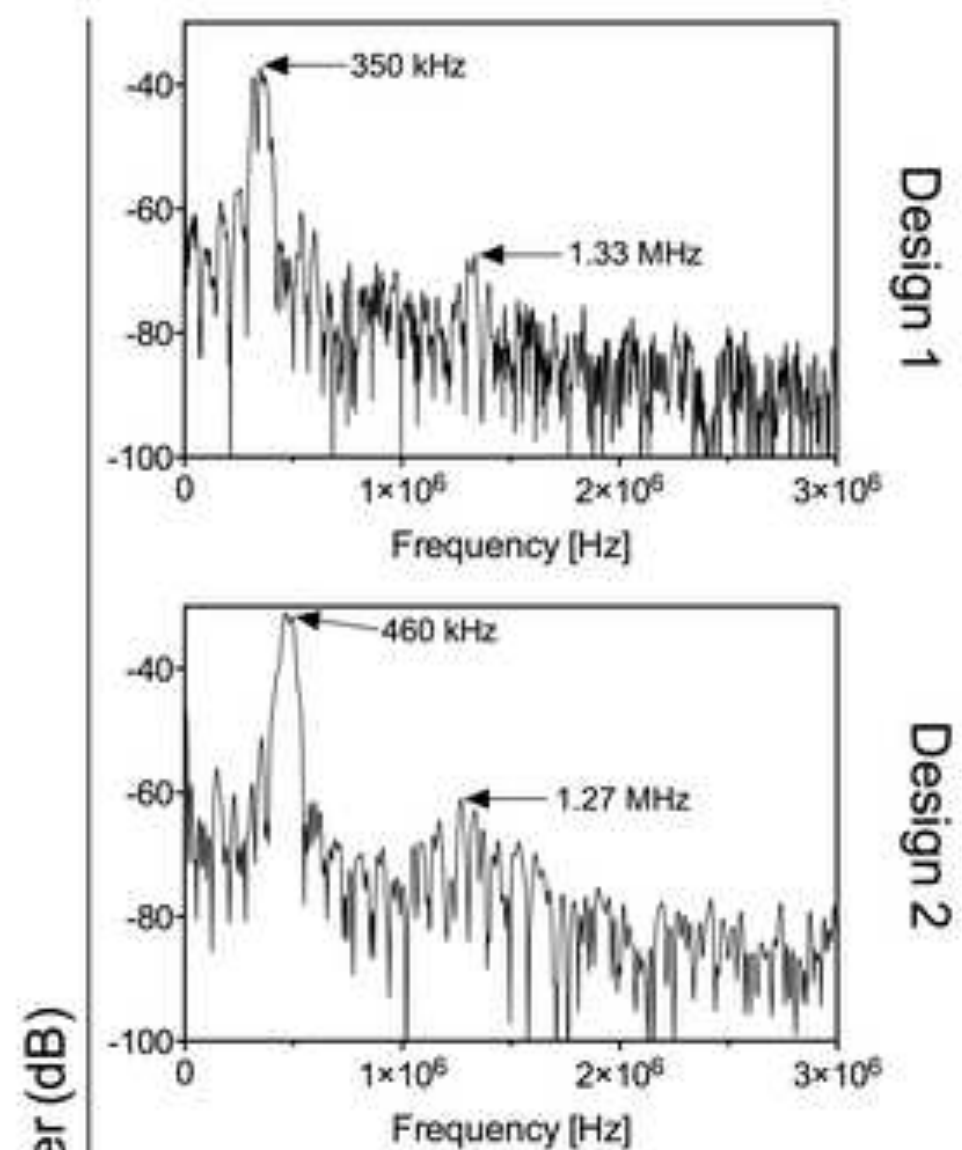

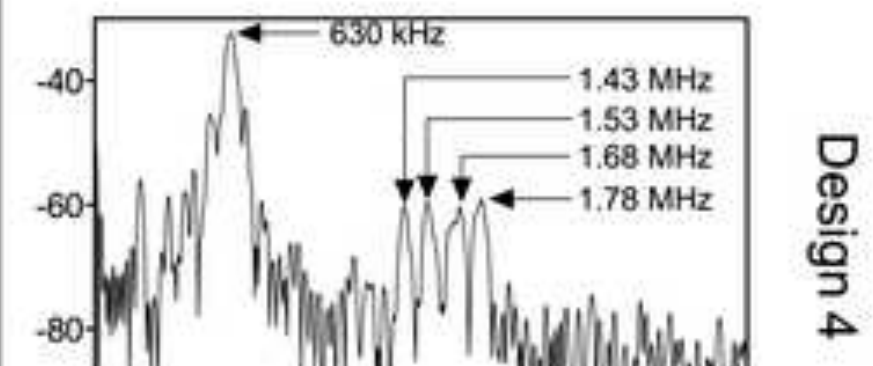



$\frac{\Phi}{\frac{8}{0}}$

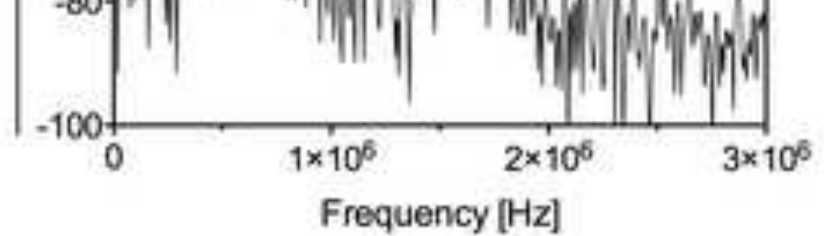

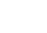



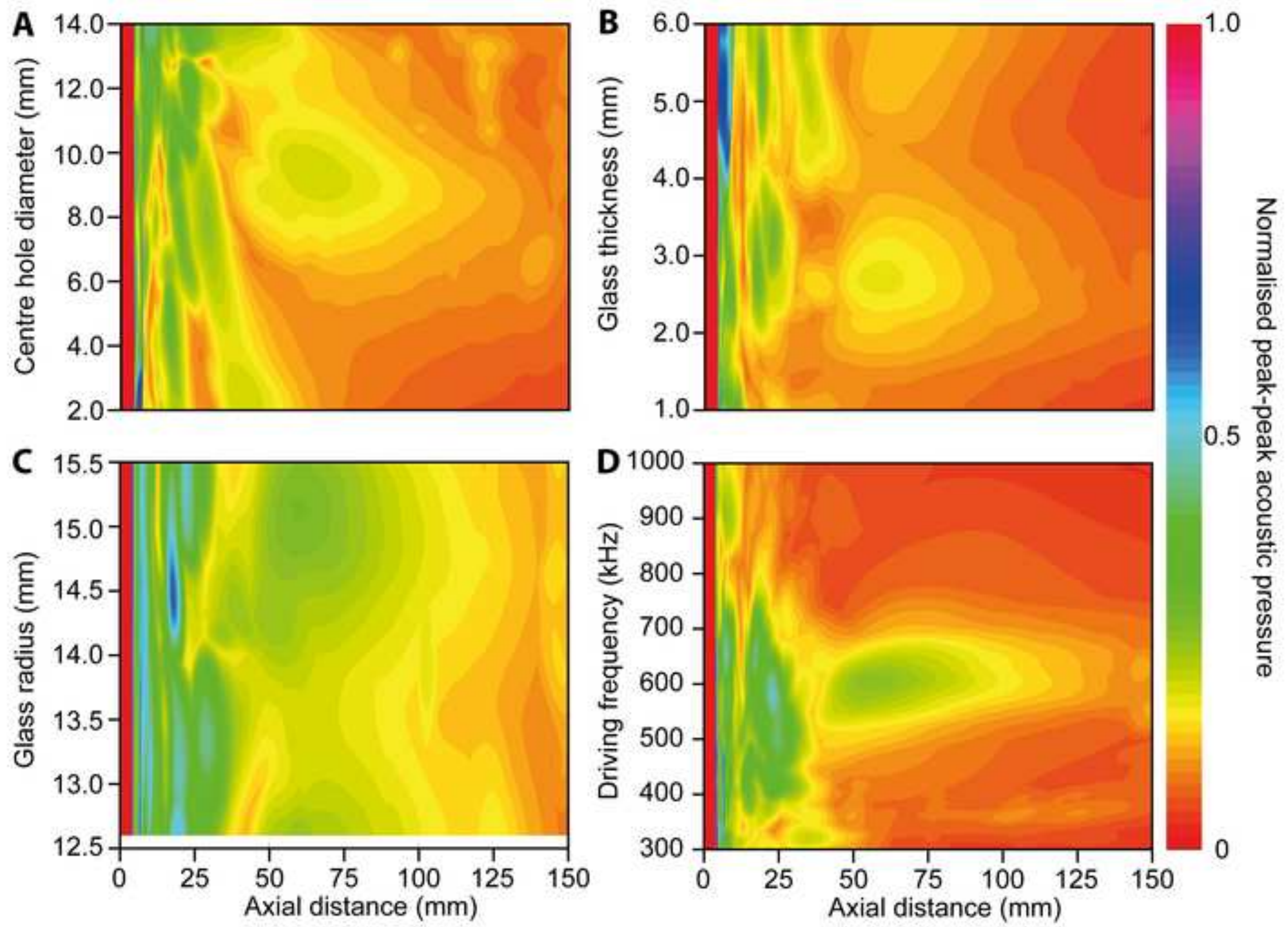
Figure_9

Click here to download high resolution image

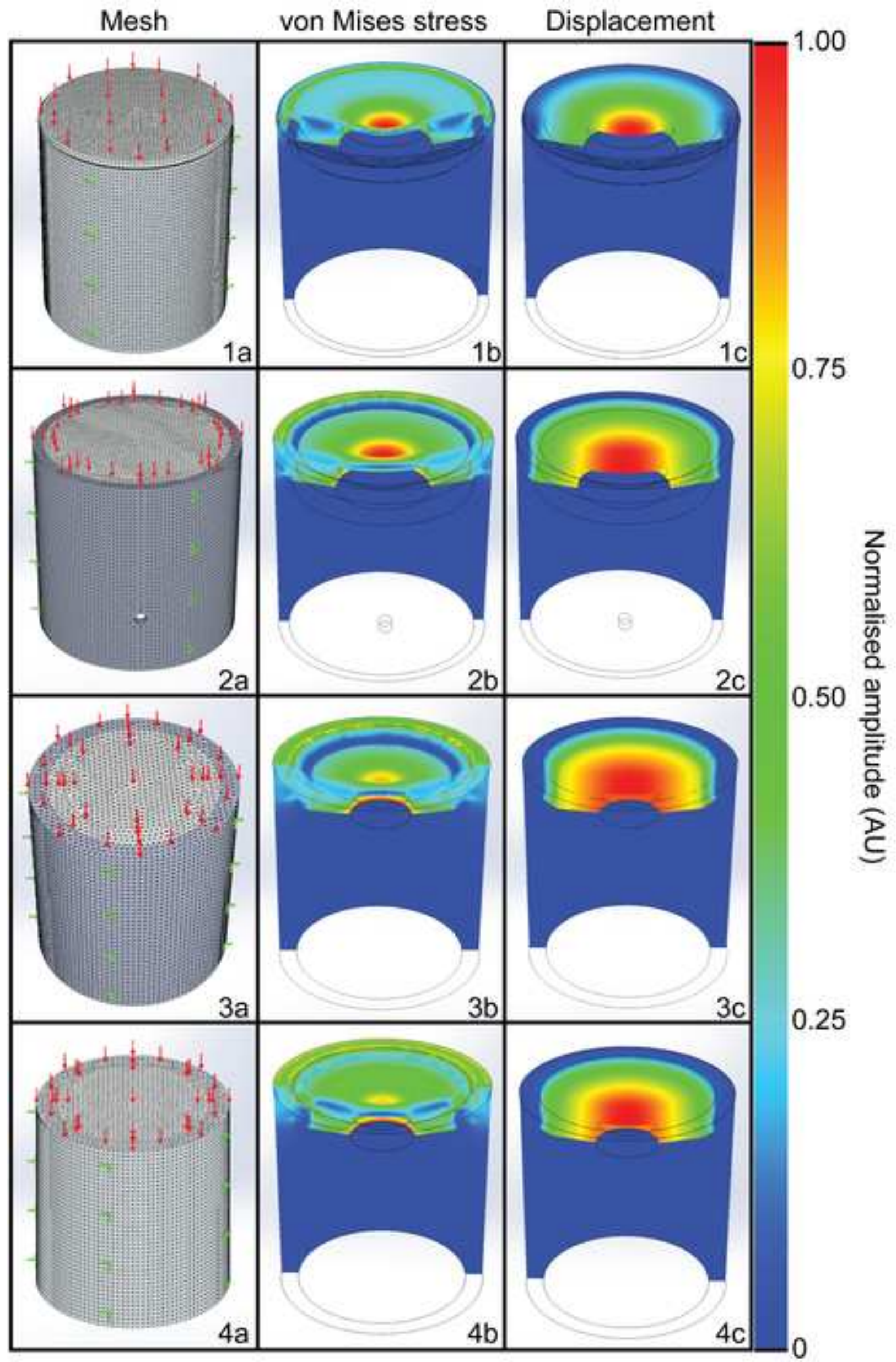


A

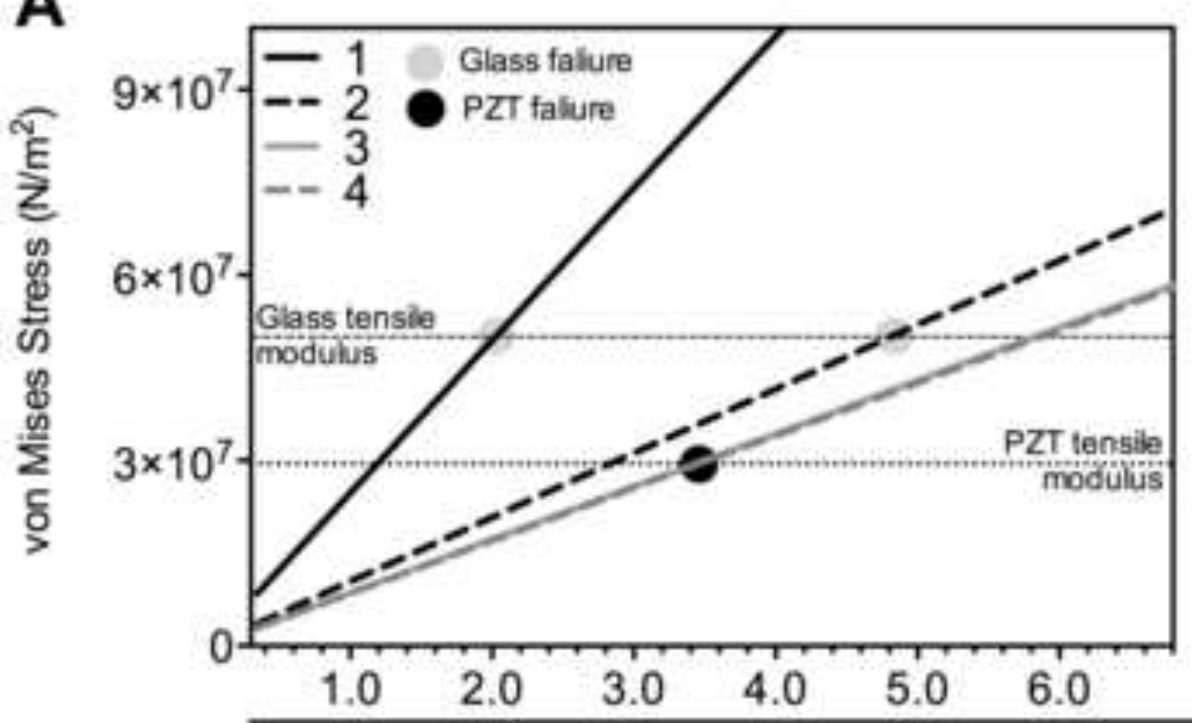

B

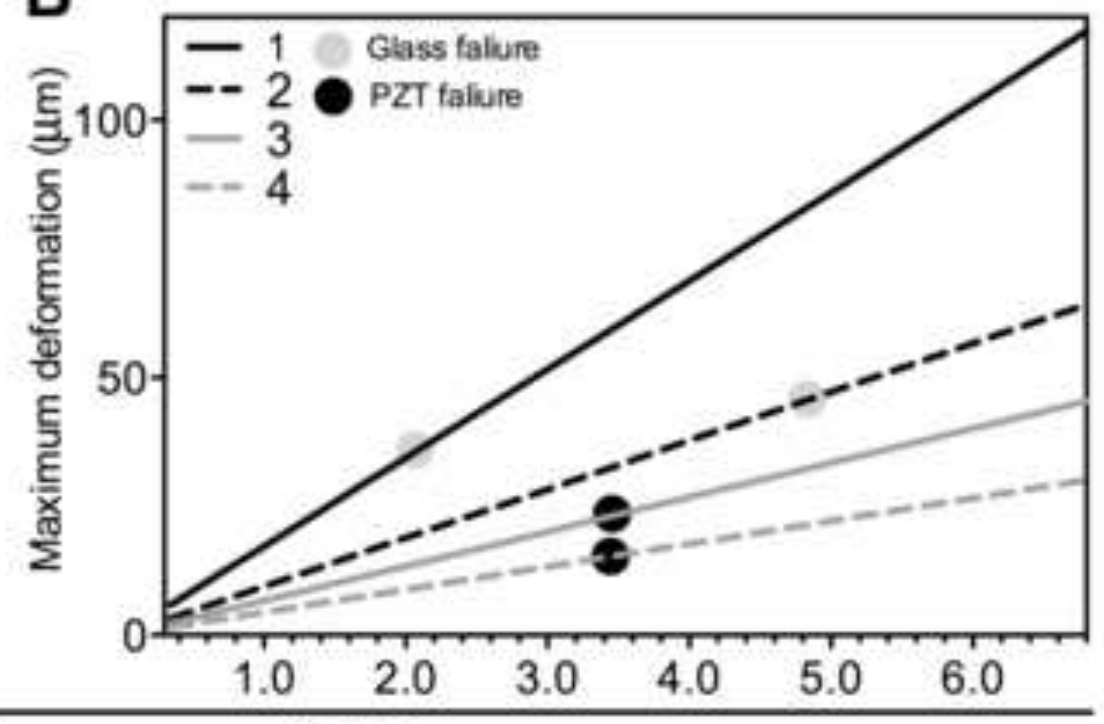

Isostatic surface pressure (MPa) 


\section{Highlights}

- An ultrasound transducer with a glass optical window constructed and simulated.

- Devices produced bandwidths $>87 \%$, powers $>1 \mathrm{~W}$, and pressures $>1 \mathrm{MPa}$.

- Finite element analysis was able to predict the acoustic pressure and beam profile. 